\title{
PARAMETRIC STUDY OF THE NON-PREMIXED COAL COMBUSTION IN FURNACE FOR HEAT TRANSFER AND EMISSION CHARACTERISTICS
}

\author{
Satish Kumar Dewangan ${ }^{1^{*}}$, Moode Praveen Kumar Naik ${ }^{1}$, Vivek Deshmukh ${ }^{1}$
}

\begin{abstract}
Steady-state turbulent non-premixed combustion of pulverized coal has been modeled in the two-dimensional furnace. Pulverized coal of three different types, low volatiles coal, medium volatile coal and high volatile coal, has been considered. The coal is injected through the center of the furnace and air is being supplied with two inlets (top inlet and bottom inlet) at different velocities. Taking advantage of the symmetry, only one half of the domain is considered. Results have been validated with the experimental data for furnace temperature distribution. Effect of variation of parameters such as top air velocity, bottom air velocity, air temperature, furnace wall temperature and mass flow rate of coal are discussed for all three different types of coal. The effect of these various parameters has been discussed upon peak temperature inside the furnace, heat transfer to/from the system to surroundings and emission of gases like compounds of $\mathrm{NO}, \mathrm{CO}$ and $\mathrm{CO}_{2}$. The analysis has been carried out using Ansys-Fluent software.
\end{abstract}

Keywords: Non-premixed Combustion, Coal Combustion, Computational Fluid Dynamics, Combustion Modeling, Pollutant Emission, Nox Emission

\section{INTRODUCTION}

In the present day, energy scenario coal stands as the main source for power generation and process industries. Effective utilization of the thermal content of the coal depends primarily upon its proper combustion. Apart from the thermal efficiency of energy generation, pollution is also one of the major concerns. Considering these two important concerns the present work is focused on investigating the factors which affect the coal combustion and pollutants getting generated in that duration.

With the increased impetus on the fast life and industrialization in the modern world, it has become imperative to have an efficient combustion process for small scale like a home needs to large scale like furnaces\& process industries. The involvement of the computational tools in modeling \& simulation of the combustion processes of various types of combustion systems and mechanisms of combustions has brought greater insight into the combustion process thus helping in improving the thermal performances of the system involving combustion as a vital part.

Various researchers have studied the combustion processes and systems by using various computational approaches. Computational modeling of the combustion is a tough task due to multiples parameters such as capturing the turbulence, capturing the convection and radiation process, complete chemical details of the fuel and capturing the chemical kinetics which is involved in computational combustion.

Holkar et al. [1] have analyzed the different radiation models for pulverized-coal combustion of burner used in the furnace. They have concluded that discrete ordinate and discrete transfer radiation models give better results than the P-1 radiation model, as they satisfy more closely the experiments conducted in similar situations.

Marek and Bartosz [2] have carried out an experimental study of single-particle combustion of Pittsburgh and SAC and Turów coal-particles in air and different oxy-fuel atmospheres, at different time steps. They have concluded that the addition of water vapor in the oxy-fuel atmosphere increased particle temperature during the combustion of coal particles.

This paper was recommended for publication in revised form by Regional Editor Baha Zafer

${ }^{1}$ Department of Mechanical Engineering, National Institute of Technology, Raipur, India

*E-mail address: skdewangan.mech@nitrr.ac.in

Orcid id: 0000-0001-6698-3247, 0000-0002-7855-6952, 0000-0002-3796-751X

Manuscript Received 12 October 2018, Accepted 9 February 2019 
Bhuiyan and Naser [3] have studied co-firing of biomass with coal under oxy-fuel combustion in a tangentially fired boiler. They have concluded that the increase in oxy-fuel conditions leads to an increase in flame temperature.

Elattar et al. [4] have studied CFD modeling of confined non-premixed jet flames in rotary kilns for various gaseous fuels like methane, carbon monoxide and biogas $\left(50 \% \mathrm{CH}_{4}\right.$ and $\left.50 \% \mathrm{CO}_{2}\right)$. They have predicted that rotary kiln flame length (confined \& jet flame lengths), heat transfer rate and peak flame temperature have a strong dependence on fuel type, excess air number, air inlet diameter, air inlet temperature, and radiation modeling.

Yu et al. [5] have experimentally \& computationally studied $\mathrm{NO}_{\mathrm{X}}$ emission characteristics, the temperature in $\mathrm{CH}_{4} /$ air non-premixed flames as a function of exhaust gas recirculation (EGR) ratio and EGR methods and found that EGR has an important role in generating the stable flames.

Ismail et al. [6] have evaluated the non-premixed combustion and fuel spray models for the in-cylinder diesel engine. The heat release rate and pressure trace have been obtained using computational simulation.

Yin [7] has studied the gas and particle radiation in pulverized fuel combustion furnaces. Weighted-sum-ofgray-gas-model (WSGGM) from Smith et al. [1982] and Yin [2013] were compared. The study reveals that the particle radiation largely overwhelms gas radiation in pulverized fuel-fired furnaces.

Gómez et al. [8] have studied the Eulerian CFD modeling for biomass combustion. Simulation of the solid and volatile ash content of the fuel and blowing effect of the outgoing gases in the convective heat \& mass exchange between the reacting particles $\&$ the surrounding gases has been considered.

Cheng et al. [9] have conducted the development and validation of a generic reduced chemical kinetic mechanism for CFD spray combustion modeling of biodiesel fuels. The methyl esters of coconut, palm, rapeseed and soybean have been prepared and tested. It was concluded that the reduced biodiesel mechanism is essentially accurate in predicting the in-cylinder ignition, combustion and extinction phenomena.

Gövert et al. [10] have conducted a comparison between RANS and LES based turbulent combustion modeling of a confined premixed jet flame including heat loss effects using tabulated chemistry. The flame length is not very accurately computed in the RANS simulations due to the underprediction of the turbulent mixing and the convective heat transfer in the shear layer. The LES fields show a good overall agreement with the experimental data and better predictions are expected with more appropriate thermal boundary conditions at the walls.

Taamallah et al. [11] have investigated the technology, fundamentals and numerical simulations of the fuel flexibility, stability and emissions in premixed hydrogen-rich gas turbine combustion. Reviews of simulations carried on using large eddy simulation model previously have been done.

Ziani et al. [12] have studied the numerical simulations of non-premixed turbulent combustion of $\mathrm{CH}_{4}-\mathrm{H}_{2}$ mixtures using the PDF approach. The authors applied the $k-\varepsilon$, modified $k-\varepsilon$ and RSM turbulent models (also compared all three models with experimental data) for the $\mathrm{CH}_{4}-\mathrm{H}_{2}$ mixtures. Results show that the modified $k-\varepsilon$ model is the most appropriate for simulating $\mathrm{CH}_{4}-\mathrm{H}_{2}$ mixtures.

$\mathrm{Li}$ et al. [13] have studied the mechanisms of NO formation in mild combustion of $\mathrm{NG} / \mathrm{H}_{2}$ and $\mathrm{CH}_{4} / \mathrm{H}_{2}$ fuel blends. Both computational fluid dynamics (CFD) and well-stirred reactor (WSR) have been used for chemical kinetics analysis.

Rahmanian et al. [14] have simulated the turbulent non-premixed pulverized coal combustion for the investigation of pollutant reduction. SIMPLE algorithm, along with the QUICK scheme for discretization of all convective terms of the advective transport equations, has been adopted to model the combustion process.

Fischer et al. [15] have studied a numerical model of the combustion of single lithium particles with $\mathrm{CO}_{2}$. The combustion model is based on experimental findings gained in a laminar flow reactor.

Zhou et al. [16] have conducted a numerical study of the influence of biofuels on the combustion characteristics and performance of an aircraft engine system. A combustion chamber with swirl-nozzle has been simulated using different biofuels like ethanol, methanol and conventional kerosene. The result shows that viscosity and calorific value are the key factors affecting the atomization and combustion characteristics of biofuels and thus affects the distribution of the temperature and NO concentration. Biofuels of low viscosity and caloric value results in better atomization effectiveness and combustion performance, respectively. When the mass flow rate of biofuels is increased the aircraft engine system adopting biofuels can obtain the same magnitude of trust as conventional fuel. 
Muppala and Manickam [17] analyzed different turbulent combustion models (Bray-Moss-Libby, LinstedtVaos (LV), a modified version LV, Turbulent Flame speed Closure, and Algebraic Flame Surface Wrinkling model) for turbulent methane/hydrogen/air combustion.

Karyeyenand Ilbas [18] have studied and describe experimental and numerical studies of low-calorific value coal gas combustion under turbulent premixed combustion conditions for the newly generated premixed burner. The results show that the nitrogen oxide emission levels increase as the hydrogen is supplied into the flame region because of the thermal nitrogen oxide mechanism. It may also be concluded that carbon dioxide levels ascend as hydrogen is supplied because of the water gas shift reaction. Hydrogen addition improves the combustion performances of the low calorific value coal gases under premixed combustion conditions.

Mao et al. [19] have done the experimental and CFD analysis of coal MILD combustion. The peak value of flame temperature decreased, and the temperature distribution became uniform. The NOx emission largely decreased due to the lower flame temperature and deoxidized atmosphere. The carbon burnout rate decreased due to the reduced particle residence time, in turn, the $\mathrm{CO}$ and oxygen concentration in the exhaust gas also increased.

Saha et al. [20] report the investigations of the impact of particle size on the MILD combustion characteristics of pulverized brown coal. In particular, the work investigates the volatiles release and reactions from the coal particles with a vitiated co-flow and its impact on the formation and emission of $\mathrm{CO}, \mathrm{CO}_{2}$, and $\mathrm{NO}_{\mathrm{x}}$.

Sudarma et al. [21] simulated the combustion processes of a mixture of lean premixed methane-air inside a bluff body stabilized gas turbine combustor using CFD. They implemented the $k-\varepsilon$ and Reynold Stress Model (RSM) in their study. They conclude that both adopted turbulence models k- $\varepsilon$ and RSM good predictions of the combustion process.

$\mathrm{Li}$ et al. [22] establish that the high proportions of both $\mathrm{H}_{2} \mathrm{O}$ and $\mathrm{CO}_{2}$ in the furnace have complex impacts on flame characteristics (ignition, burnout, and heat transfer), pollutant emissions (NOx, SOx, and particulate matter). Then, the correlations of combustion-generated particulate/NO $\mathrm{x}$ emissions with changes of combustion characteristics in both air and oxy-fuel firing modes are summarized. Fundamental oxy-fuel combustion research may provide an ideal alternative for validating CFD simulations toward industrial applications.

Abay et al.[23] performed a CFD analysis of flow and combustion in a diesel engine using the commercial

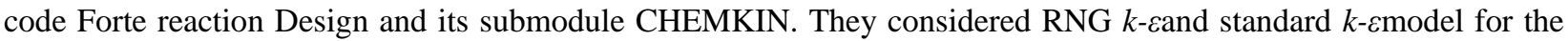
simulation. They found the optimum soot and $\mathrm{NO}_{\mathrm{x}}$ formation for the $8.5 \%$ EGR usage.

Angeline et al.[24] worked on the generation of electrical energy using the recovered heat from the combustion of syngas. They implemented the Artificial Neural Network to predict its performance using the Matlab code.

Naik and Dewangan [25] on their earlier work applied Rosin-Rammler size distribution law. They concluded air inlet velocity increases the peak temperature inside the furnace decreases, the furnace length occupied for burnout increases, the peak value of mean mixture fraction decreases, and the total heat transfer rate decreases and then increases

Based on the above-detailed literature review of investigations of different authors, it was found that combustion analysis of different types of coal, comparison between them and effect of parametric variation on different parameters like temperature, heat transfer rate, emission of gases, etc. have been paid very little attention. Considering the same, present investigation have been focused on the analysis of the effect of different parametric variation (like air velocity, air temperature, wall temperature, the mass flow rate of coal) on different parameters (like temperature, heat transfer rate, emission of gases) for different types of coal viz., low volatiles, medium volatile and high volatile coal and comparison between them.

The present investigation focuses on modeling the non-premixed combustion of pulverized coal in a blast furnace of two-dimensional simplifications. In the blast furnace, the pulverized coal is injected at the middle part along with an oxidizer to have efficient combustion. This increases heat release rate, an increase in the reduction of exhaust gases like compounds of nitrogen, compounds of carbon. Knowledge of the generation rate of these pollutants may help explore their adverse effect on the environment. To model the system in the simplified manner the blast furnace has been assumed to be a two-dimensional furnace wherein the pulverized coal is being injected from the center of the 
furnace inlet surface and the air is supplied from the inlet in two different streams which are surrounding the coal injection point. To simplify the system further, the idea of symmetry has been used.

The objective of the present investigation is the computational parametric study of the heat transfer \& emission characteristics for the non-premixed coal combustion in the furnace. To this end, the various important furnace parameters such as airflow velocity (top \& bottom both), supply or inlet air temperature, the prevailing furnace wall temperature and supply mass flow rate of coal have been investigated for all three varieties of coal. The effect of variation in these operating parameters has been explored upon peak temperature inside the furnace, heat transfer between the system \& surroundings and emission of gaseous compounds such as $\mathrm{NO}, \mathrm{CO}$ and $\mathrm{CO}_{2}$. This computational investigation has been performed using Ansys-Fluent software.

To simulate the combustion within the combustion chamber, the domain of the combustion chamber of the furnace has been idealized as a two-dimensional duct shape of height $h=1 \mathrm{~m}$ and length $w=10 \mathrm{~m}$ (figure 1). Pulverized coal is being injected through the central spray. The inlet is divided into two sections, as the situations present in the blast furnace bottom inlet $\left(h_{1}\right)$ and top inlet $\left(h_{2}\right)$. Thus air/oxidizer is supplied with two different velocities from these two different inlets. Low-speed air stream enters with a velocity of $15 \mathrm{~m} / \mathrm{sat}$ a temperature of $1500 \mathrm{~K}$ and spans 0.125 $\mathrm{m}$. High-speed air stream enters with a velocity of $50 \mathrm{~m} / \mathrm{s}$ at a temperature of $1500 \mathrm{~K}$ and spans $0.375 \mathrm{~m}$.

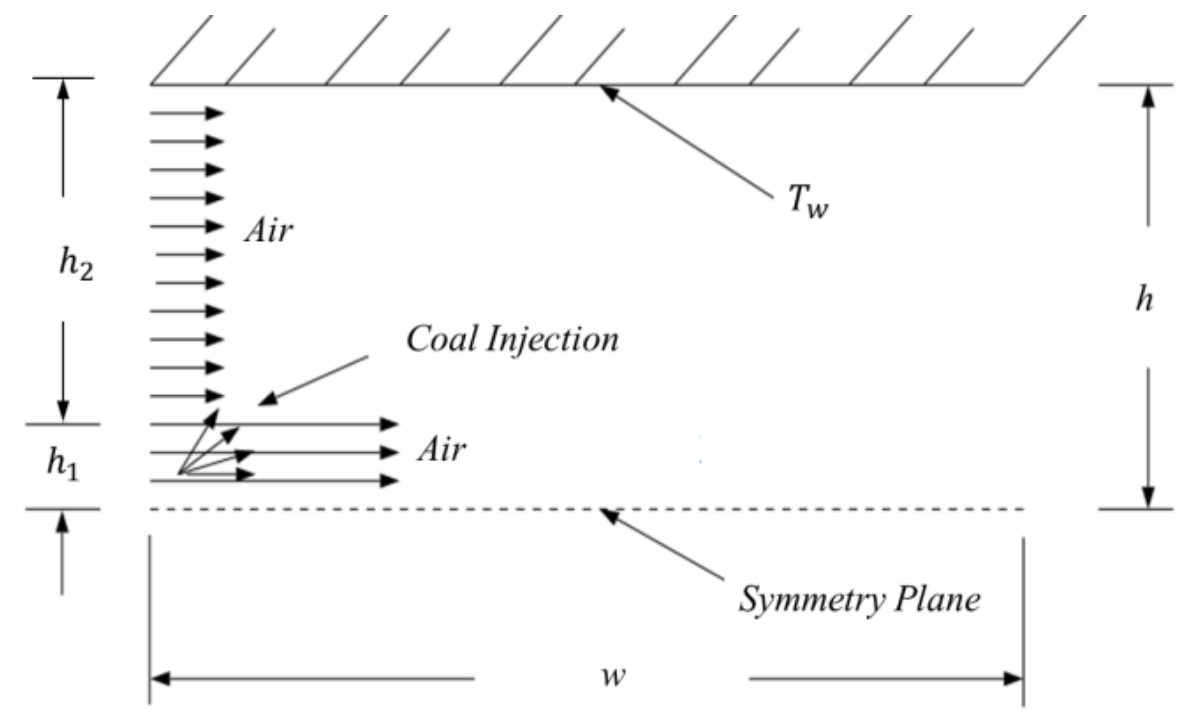

Figure 1. Basic geometry of the physical system (blast furnace combustion chamber)

Considering the symmetry only half part has been considered. The present work aims to explore the effect of the bottom air inlet velocity on various output parameters such as temperature distribution within the furnace, heat transfer rate, char burn out and mean mixture fraction distribution of injected coal within the furnace. The bottom air inlet velocity is varied and its effect on the various output parameters is studied. The total mass flow rate of coal (at the center of the high-speed stream) in the furnace has been kept at $0.1 \mathrm{~kg} / \mathrm{s}$.

\section{MATHEMATICAL FORMULATION}

The mathematical formulation [ANSYS-Fluent Manual] of the governing equations for the present steady 2D turbulent combustion in the furnace is as follows;

Steady-state continuity equation:

$$
\frac{\partial}{\partial x_{i}}\left(\rho u_{i}\right)=S_{m 1}
$$


where source term $\left(S_{m 1}\right)$ results solely due to the transfer of mass into the gas phase from the combustion of the reacting particles (e.g. here the injected coal particles). This is the net production rate of the species per unit volume associated with the chemical reaction.

Three-dimensional momentum equation:

$$
\frac{\partial}{\partial x_{j}}\left(\rho u_{i} u_{j}\right)=-\frac{\partial p}{\partial x_{j}}+\frac{\partial \tau_{i j}}{\partial x_{j}}+\rho g_{i}+F_{i}+S_{m 2}
$$

The terms in the right-hand side of the above equation include pressure forces $\frac{\partial p}{\partial x_{j}}$, turbulent shear forces $\frac{\partial \tau_{i j}}{\partial x_{j}}$, and gravitational force $\rho g_{i}$ and source term $S_{m 2}$. Here the source term $S_{m 2}$ is the contribution of the gaseous species generated in the force balance which is quite negligible.

Species transport equations [ANSYS-Fluent Manual]:

(a) Convection-diffusion equation

Local mass fraction of each species $Y_{j}$ through the solution of convection-diffusion equation for the $j^{\text {th }}$ species,

$$
\nabla\left(\rho \bar{v} Y_{j}\right)=-\nabla \cdot \vec{J}_{j}+R_{j}+S_{j}
$$

where $\vec{J}_{j}, R_{j}, S_{j}$ are diffusion flux of species $j$, net rate of production of species $j$ by chemical reaction and rate of creation by addition from the dispersed phase respectively. Mass fraction of all the species must be equal to 1.0.

(b) Mass diffusion in turbulent flows:

Mass diffusion occurs due to the gradient of concentration and temperature. This is below,

$$
\vec{J}_{j}=-\left(\rho D_{j, m}+\frac{\mu_{t}}{S c_{t}}\right) \nabla Y_{j}-D_{T, j} \frac{\nabla T}{T}
$$

where, $S c_{t}=\frac{\mu_{t}}{\rho D_{t}}$. The default value of $S c_{t}$ is 0.7 .

(c) Mixture fraction (f):

Written in terms of mass fractions of species $j, Y_{j}$, as

$$
f=\frac{Y_{j}-Y_{j, o x}}{Y_{j, f u e l}-Y_{j, o x}}
$$

where $Y_{j, O x}, Y_{j, f u e l}$, are mass fractions of oxidizing species and fuel respectively.

$f=1$ at fuel stream.

$f=0$ at oxidizer stream.

$f=(0-1)$ within the flow.

(d) Mean mixture fraction $(\bar{f})$ :

$$
\nabla\left(\rho u_{j} \bar{f}\right)=\nabla\left(\frac{\mu_{t}}{\sigma_{t}} \nabla \bar{f}\right)+S_{m 3}
$$

The source term $S_{m 3}$ is the mass production or consumption rate per unit volume of the species generated or the coal burnt.

(e) Mean mixture fraction variance $\left(\overline{f^{\prime 2}}\right)$ :

$$
\nabla \cdot\left(\rho u_{j} \overline{f^{\prime 2}}\right)=\nabla \cdot\left(\frac{\mu_{t}}{\sigma_{t}} \nabla \overline{f^{\prime 2}}\right)+C_{g} \mu_{t}(\nabla \bar{f})^{2}-C_{d} \rho \frac{\varepsilon}{k} \overline{f^{\prime 2}}
$$


where $f^{\prime}=f-\bar{f}$. The default values of the constants $\sigma_{t}, C_{g}$, and $C_{d}$ are $0.85,2.86$ and 2.0 respectively.

Under the assumption of chemical equilibrium, all the thermochemical scalars (mass fractions, density and temperature) depend solely on the instantaneous mixture fraction $f$ : For non-adiabatic systems (in this case):

$$
\emptyset_{i}=\emptyset_{i}(f, H)
$$

Where $H$ is the instantaneous enthalpy. The average values related to the instantaneous values depend on the turbulence-chemistry interaction model which is governed by the probability density function (PDF) Model written as $p(f)$ in non-premixed combustion. $p(f)$ can be generalized as a fraction of time that the fluid spends in the vicinity of the state $f$. The time-averaged mean mass fraction of species and temperature is computed for the non-adiabatic system as;

$$
\bar{\emptyset}_{\iota}=\int_{0}^{1} p(f) \emptyset_{i}(f, \bar{H}) d f
$$

Also time-averaged fluid density can be computed as

$$
\begin{gathered}
\frac{1}{\bar{\rho}}=\int_{0}^{1} \frac{p(f)}{\rho(f)} d f \\
p(f)=\frac{f^{\alpha-1}(1-f)^{\beta-1}}{\int f^{\alpha-1}(1-f)^{\beta-1} d f} \\
\alpha=\bar{f}\left[\frac{\bar{f}(1-\bar{f})}{\bar{f}^{\prime 2}}-1\right] \\
\beta=(1-\bar{f})\left[\frac{\bar{f}(1-\bar{f})}{\overline{f^{\prime 2}}}-1\right]
\end{gathered}
$$

for a single mixture fraction system.

(f) Mean enthalpy $(\bar{H})$ form of the energy equation:

$$
\nabla \cdot(\rho \vec{v} \bar{H})=\nabla \cdot\left(\frac{k_{t}}{c_{p}} \nabla \bar{H}\right)+S_{h}
$$

where $\bar{H}=\sum_{j} Y_{j} H_{j}$.

$$
H_{j}=\int_{T_{r e f, j}}^{T} c_{p, j} d T+h_{j}^{0}\left(T_{r e f, j}\right)
$$

$h_{j}^{0}\left(T_{r e f, j}\right)$ is the formation enthalpy of species $\mathrm{j}$ at the reference temperature $T_{r e f, j}$. Source term $S_{h}$ in the above equation includes combustion and radiation heat transfer rates.

(g) Inert heating law:

The inert heating law is applied while the particle temperature is less than the devolatilization temperature. A simple heat balance is applied to relate the particle temperature $T_{p}(t)$, to the convective heat transfer and the absorption/emission of radiation at the particle surface:

$$
m_{p} C_{p} \frac{d T_{p}}{d t}=h A_{p}\left(T_{\infty}-T_{p}\right)+A_{p} \varepsilon_{p} \sigma\left(\theta_{R}^{4}-T_{p}^{4}\right)
$$


where $\theta_{\mathrm{R}}$ is radiation temperature defined by $\left(\frac{I}{4 \sigma}\right)^{1 / 4}$. The above equation is valid for the coal particle at a uniform temperature.

(h) Devolatilization model: single rate

Devolatilization law is applied when the temperature of the particle reaches the onset devolatilization temperature and remains in effect while the mass of the particle exceeds the mass of the non-volatiles in the particle. The single kinetic rate devolatilization model assumes that the rate of devolatilization is the first-order dependent on the amount of volatiles remaining in the particle.

$$
-\frac{1}{f_{v, 0}\left(1-f_{w, 0}\right) m_{p, 0}} \frac{d m_{p}}{d t}=A_{0}
$$

The value of $A_{0}$ is $12 \mathrm{~s}^{-1}$ is derived from the work of Pillai [26] on coal combustion.

(i) Combustion model: kinetics/diffusion limited

After the volatile component of the particle completely evolved a surface reaction is starts, by consuming the combustible fraction of the particle. When the combustible fraction has been consumed, the combusting particle contains residual ash that reverts to the inert heating law. The surface combustion reaction consumes the reactive content of the particle is governed by the stoichiometric requirement, $S_{b}$, of the surface burnout reaction.

$$
\text { Char (s) }+S_{b} O_{g} \rightarrow \text { Products }(g)
$$

where $S_{b}$ is defined in terms of the mass of oxidant per mass of char. Model of Baum, Street and Field in which, Diffusion rate coefficient,

$$
D_{0}=C_{1} \frac{\left[\left(T_{p}+T_{\infty}\right) / 2\right]^{0.75}}{d_{p}}
$$

Kinetic rate,

$$
\mathrm{R}=C_{2} e^{-\left(E / R T_{p}\right)}
$$

are used to yield a char combustion rate of

$$
\frac{d m_{p}}{d t}=-A_{p} p_{o x} \frac{D_{0} \mathrm{R}}{D_{0}+\mathrm{R}}
$$

in which $R$ incorporates the effects of chemical reaction on the internal surface of the char particle and pore diffusion.

(j) Heat and mass transfer during char combustion:

$$
m_{p} c_{p} \frac{d T_{p}}{d t}=h A_{p}\left(T_{\infty}-T_{p}\right)-f_{h} \frac{d m_{p}}{d t} H_{r e a c}+A_{p} \varepsilon_{p} \sigma\left(\theta_{R}^{4}-T_{p}^{4}\right)
$$

$H_{\text {reac }}$ is the heat released by the surface reaction. Only a portion $\left(1-f_{h}\right)$ of the energy produced by the surface reaction appears as a heat source in the gas-phase energy equation. The particle absorbs a fraction $f_{h}$ of this heat directly. $f_{h}$ set to be 1.0 if char burnout product is $\mathrm{CO}$ and 0.3 for $\mathrm{CO}_{2}$.

P-1 radiation model is used to calculate the flux of the radiation inside the furnace. Heat sources due to radiation can be calculated by substituting $-\nabla q_{r}=\alpha G-4 \alpha n^{2} \sigma T^{4}$, directly into the energy equation. In equation (22) the absorption coefficient $(\alpha)$ is computed from weighted-sum-of-gray-gases-models. 
(k) Turbulence modeling: standard $k-\varepsilon$ model

The standard $k$ - $\epsilon$ model is a semi-empirical model based on model transport equations for the turbulence kinetic energy $(k)$ and its dissipation rate $(\epsilon)$. The model transport equation for $k$ is derived from the exact equation, while the model transport equation for $\epsilon$ is obtained using physical reasoning and bears little resemblance to its mathematical counterpart.

In the derivation of the $k-\epsilon$ model, the flow is assumed to be fully turbulent and the effects of molecular viscosity are considered negligible. The standard $k-\epsilon$ model is therefore valid only for fully turbulent flows.

Transport equations for the standard $k$ - $€$ model [ANSYS-Fluent Manual]:

The turbulence kinetic energy $k$ and its rate of dissipation $\epsilon$ are obtained from the following transport equations:

$$
\begin{aligned}
& \frac{\partial}{\partial t}(\rho k)+\frac{\partial}{\partial x_{i}}\left(\rho k u_{i}\right)=\frac{\partial}{\partial x_{j}}\left[\left(\mu+\frac{\mu_{t}}{\sigma_{k}}\right) \frac{\partial k}{\partial x_{j}}\right]+G_{k}+G_{b}-\rho \epsilon-Y_{M}+S_{k} \\
& \frac{\partial}{\partial t}(\rho \epsilon)+\frac{\partial}{\partial x_{i}}\left(\rho \epsilon \mu_{i}\right)=\frac{\partial}{\partial x_{j}}\left[\left(\mu+\frac{\mu_{t}}{\sigma_{\epsilon}}\right) \frac{\partial \epsilon}{\partial x_{j}}\right]+C_{1 \epsilon} \frac{\epsilon}{k}\left(G_{k}+C_{3 \epsilon} G_{b}\right)-C_{2 \epsilon} \rho \frac{\epsilon^{2}}{k}+S_{\epsilon}
\end{aligned}
$$

In these equations, $G_{k}$ represents the generation of turbulence kinetic energy due to the mean velocity gradients, $G_{b}$ is the generation of turbulence kinetic energy due to buoyancy, $Y_{M}$ represents the contribution of the fluctuating dilatation in compressible turbulence to the overall dissipation rate, $C_{1 \epsilon}, C_{2 \epsilon}$, and $C_{3 \epsilon}$ are constants. $\sigma_{k}$ and $\sigma_{\epsilon}$ are the turbulent Prandtl number for $\mathrm{k}$ and $\epsilon$, respectively. $S_{k}$ and $S_{\epsilon}$ are user-defined source terms.

Modeling the turbulent viscosity [ANSYS-fluent manual]:

The turbulent (or eddy) viscosity, $\mu_{t}$, is computed by combining $k$ and $\epsilon$ as follows:

$$
\mu_{t}=\rho C_{\mu} \frac{k^{2}}{\epsilon}
$$

where $C_{\mu}$ is a constant.

Table 1. Model constant used in the present simulation

\begin{tabular}{|c|c|c|c|c|}
\hline$C_{1 \epsilon}$ & $C_{2 \epsilon}$ & $\mathrm{C}_{\mu}$ & $\sigma_{k}$ & $\sigma_{\epsilon}$ \\
\hline 1.44 & 1.92 & 0.09 & 1.0 & 1.3 \\
\hline
\end{tabular}

These default values have been determined from experiments with air and water for fundamental turbulent shear flows including homogeneous shear flows and decaying isotropic grid turbulence. They have been found to work fairly well for a wide range of wall-bounded and free shear flows.

(l) PARTS PER MILLION (PPM):

$$
p p m=\frac{\text { molefractionof species } * 10^{6}}{\left(1-\text { molefractionof } \mathrm{H}_{2} \mathrm{O}\right)}
$$

\section{NUMERICAL MODELLING, MESH INDEPENDENCE STUDY AND VALIDATION}

Computational mesh with the boundary conditions has been shown in figure 2. These parameters have been used in simulation using ANSYS Fluent. The mesh considered for modeling is a structured mesh with quadrilateral cells, its details are given in table 5 .

The following boundary conditions have been specified for the computational domain;

(a) Top air inlet: Air enters into the furnace with an axial velocity of $15 \mathrm{~m} / \mathrm{s}$ at a temperature of $1500 \mathrm{~K}$, spanning a height $\left(h_{2}\right)$ of $0.375 \mathrm{~m}$. 
(b) Bottom air inlet: Air enters into the furnace with an axial velocity of $50 \mathrm{~m} / \mathrm{s}$ at a temperature of $1500 \mathrm{~K}$, spanning a height $\left(h_{1}\right)$ of $0.25 \mathrm{~m}$.

(c) Coal particles are injected with a mass flow rate of $0.1 \mathrm{~kg} / \mathrm{sat}$ the one-fourth span of the bottom air inlet from the symmetry plane.

(d) Outlet boundary condition is the pressure outlet with a backflow temperature of $2000 \mathrm{~K}$.

(e) Top boundary is a constant wall temperature boundary with a temperature of $1200 \mathrm{~K}$.

(f) Bottom boundary is a symmetry plane so that furnace is symmetric about the $\mathrm{x}$-axis.

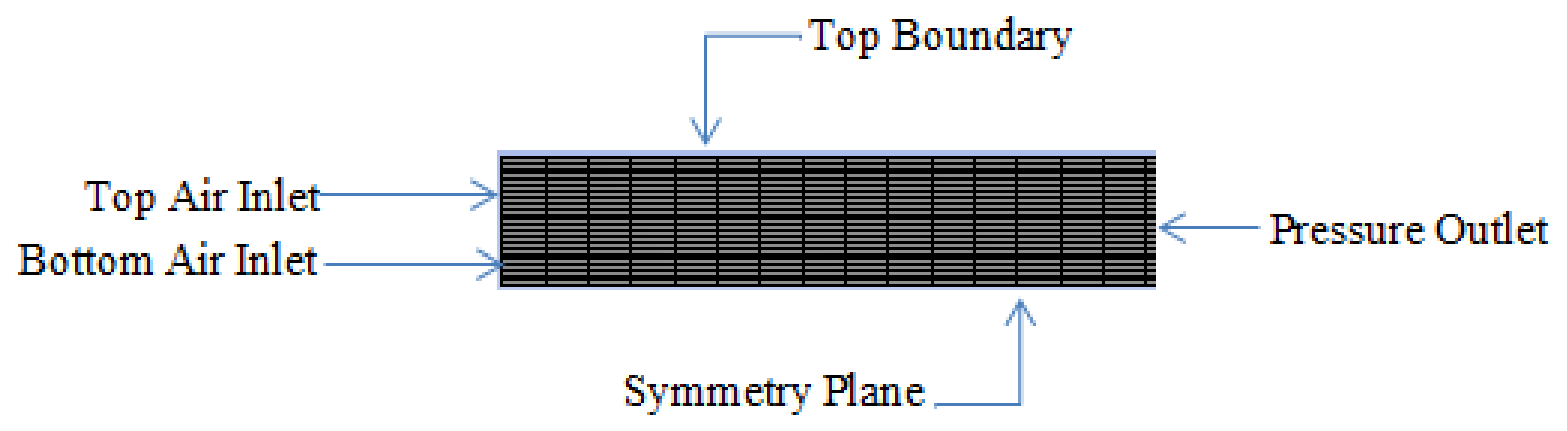

Figure 2. View of mesh of the two-dimensional model of furnace

SIMPLE algorithm has been used for pressure velocity coupling. As the study focuses on the two-dimensional geometry with axisymmetric condition assuming the flow to be fully turbulent because of high temperature due to combustion [ANSYS Theory Guide]. The standard k- $\varepsilon$ turbulent model is used. The proximate and ultimate analysis of the empirical fuel (where devolatilization of coal starts at $400 \mathrm{~K}$ ) stream in the form of mole fractions of different species is shown in table 1.Empirical model allows defining fuel composition in terms of ultimate analysis (atomic fractions of $\mathrm{C}, \mathrm{H}, \mathrm{O}, \mathrm{N}$, and $\mathrm{S}$ ), along with the lower heating value and heat capacity (3.53x10 $\mathrm{J} / \mathrm{kg}$ and $1000 \mathrm{~J} / \mathrm{kg}-\mathrm{k}$ respectively). Oxides consist of $\mathrm{N}_{2}$ and $\mathrm{O}_{2}$ with the mole fraction of 0.78992 and 0.21008 respectively and with an inlet temperature of $1500 \mathrm{~K}$ (corresponding inlet temperature of the air). Considering inlet diffusion (inlet flux of particles taken into account), a probability density function (PDF) table has been created in which the enthalpy field is initialized, the temperature limits, the stoichiometric mixture fractions are calculated, and the enthalpy grid has been adjusted to account for the solution parameters. Mean values of temperature, composition, and density at the discrete mixture fraction/mixture-fraction-variance/enthalpy points are then calculated. The result is a set of tables containing mean values of species mole fractions, density, and temperature at each discrete value of these three parameters.

The discrete phase model is used for predicting trajectories of individual coal particles, each representing a continuous stream of coal. Heat, momentum, and mass transfer exchange between the coal and the gas is included by alternately computing the discrete phase trajectories and the gas phase continuity equations. Interaction with continuous phase is chosen so that discrete phase trajectories are allowed to impact on gas-phase equations. Particle radiation interaction is used to enable the effect of radiation on particles. [Ansys-Fluent manual]

Coal particles are injected at the one-fourth of bottom air inlet from the symmetry plane with a different number of streams (same properties but with different spherical sizes which follows Rosin-Rammler size distribution, diameter size ranging from 70 microns to 200 microns). Axial velocity, radial velocity, temperature and oxidizing species considered are $10 \mathrm{~m} / \mathrm{s}, 5 \mathrm{~m} / \mathrm{s}, 300 \mathrm{~K}$ and $\mathrm{O}_{2}$ respectively. A discrete random walk model is chosen for stochastic tracking for turbulent dispersion. Stochastic tracks model the effect of turbulence in the gas phase on the particle trajectories. Properties of coal particles are shown in table 2 . For continuous phase material, thermal conductivity and viscosity are $0.025 \mathrm{~W} / \mathrm{m}-\mathrm{K}$ and $2 \times 10^{5} \mathrm{~kg} / \mathrm{m}$-s respectively. Other properties like specific heat, density, formation enthalpies are computed from PDF and mixing laws. For spatial discretization different schemes are used as shown in table 3.Underrelaxation factors are shown in table 4.Operating pressure is $1 \mathrm{~atm}$. A maximum residual convergence of $10^{-5}$ has been 
set to govern variables. Under the above-mentioned conditions, mesh independent study was done for temperature distribution at an axial location of $6 \mathrm{~m}$ by considering different mesh sizes as described in Table 5. A plot of radial distance versus temperature at an axial location of $6 \mathrm{~m}$ is shown in Figure 3.

Table 2. Mole fractions of species of the fuel stream

\begin{tabular}{|c|c|c|c|c|}
\hline Species & $\mathrm{C}$ & $\mathrm{H}$ & $\mathrm{O}$ & $\mathrm{N}$ \\
\hline Mole Fractions & 0.581 & 0.390 & 0.016 & 0.013 \\
\hline
\end{tabular}

Table 3. Properties of coal particles

\begin{tabular}{|l|l|l|c|}
\hline \multicolumn{1}{|c|}{ Properties } & \multicolumn{1}{c|}{ Values } & \multicolumn{1}{c|}{ Properties } & Values \\
\hline Density $\left(\mathrm{kg} / \mathrm{m}^{3}\right.$ ) & 1300 & Particle scattering factor & 0.6 \\
\hline Specific heat $(\mathrm{j} / \mathrm{kg}-\mathrm{k})$ & 1000 & Swelling coefficient & 2 \\
\hline Vaporization temperature (K) & 400 & Burnout stoichiometric ratio & 2.67 \\
\hline Volatile component fraction (\%) & 28 & Combustible fraction (\%) & 64 \\
\hline Binary diffusivity (m²/s) & 0.0005 & Devolatilization model (1/s) & Single rate \\
\hline Particle emissivity & 0.9 & Combustion model & $\begin{array}{c}\text { Kinetics/diffusi } \\
\text { on limited }\end{array}$ \\
\hline
\end{tabular}

Table 4. Spatial discretization schemes

\begin{tabular}{|l|l|l|l|}
\hline \multicolumn{1}{|c|}{ Entity } & \multicolumn{1}{|c|}{ Scheme } & \multicolumn{1}{c|}{ Entity } & \multicolumn{1}{c|}{ Scheme } \\
\hline Gradient & Least squares cell based & $\begin{array}{l}\text { Turbulent dissipation } \\
\text { rate }\end{array}$ & First order upwind \\
\hline Pressure & Second order & Energy & Second order upwind \\
\hline Momentum & Second order upwind & Mean mixture fraction & Second order upwind \\
\hline $\begin{array}{l}\text { Turbulent kinetic } \\
\text { energy }\end{array}$ & First order upwind & $\begin{array}{l}\text { Mixture fraction } \\
\text { variance }\end{array}$ & Second order upwind \\
\hline
\end{tabular}

Table 5. Under-relaxation factors

\begin{tabular}{|l|c|l|c|}
\hline \multicolumn{1}{|c|}{ Parameters } & Values & \multicolumn{1}{c|}{ Parameters } & Values \\
\hline Pressure & 0.3 & Turbulent viscosity & 1 \\
\hline Momentum & 0.7 & Energy \&temperature & 1 \\
\hline Density & 1 & P-1 Model & 1 \\
\hline Body forces & 1 & Mean mixture fraction & 0.9 \\
\hline Turbulent kinetic energy & 0.8 & Mixture fraction variance & 0.5 \\
\hline Turbulent dissipation rate & 0.8 & DPM sources & \\
\hline
\end{tabular}

Table 6. Divisions of meshes

\begin{tabular}{|c|c|c|}
\hline $\begin{array}{c}\text { No. of divisions along axial } \\
\text { direction }\end{array}$ & $\begin{array}{c}\text { No. of divisions along transverse } \\
\text { direction }\end{array}$ & $\begin{array}{c}\text { Final mesh size } \\
\text { (all are quadrilateral cells) }\end{array}$ \\
\hline 1000 & 50 & 50000 \\
\hline 1000 & 60 & 60000 \\
\hline 1000 & 70 & 70000 \\
\hline 1000 & 80 & 80000 \\
\hline 1000 & 90 & 90000 \\
\hline
\end{tabular}


Journal of Thermal Engineering, Research Article, Vol. 6, No. 6, Special Issue 12, pp. 323-353,

December, 2020

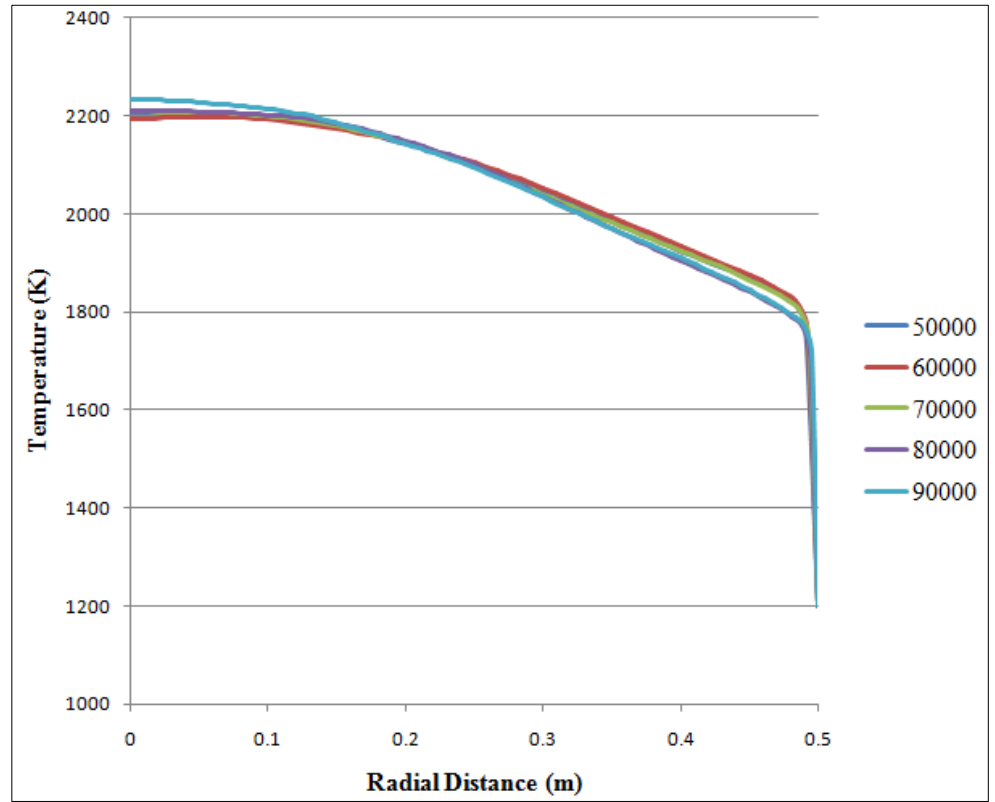

Figure 3. Radial variation of the furnace temperature at an axial location of $6 \mathrm{~m}$

As seen from figure 3 , for all the mesh sizes, the temperature is maximum at a radial distance of zero, decreases as radial distance increases and reached the temperature of the wall (at a radial distance of $0.5 \mathrm{~m}$ ). It is obvious at the symmetry line the concentration of temperature is more because flame travels axially impacting effect at the center due to coal injection which occurred at the center. It can be concluded that as the distance opposite to the flame direction increases (where the concentration of coal particles is less), the temperature decreases. From figure 3, since all the mesh cases are almost matching together thus to have a balanced approach between the computational time and possibility of any complexity in the flow physics of the domain, the mesh size of 80000 has been considered for the final study

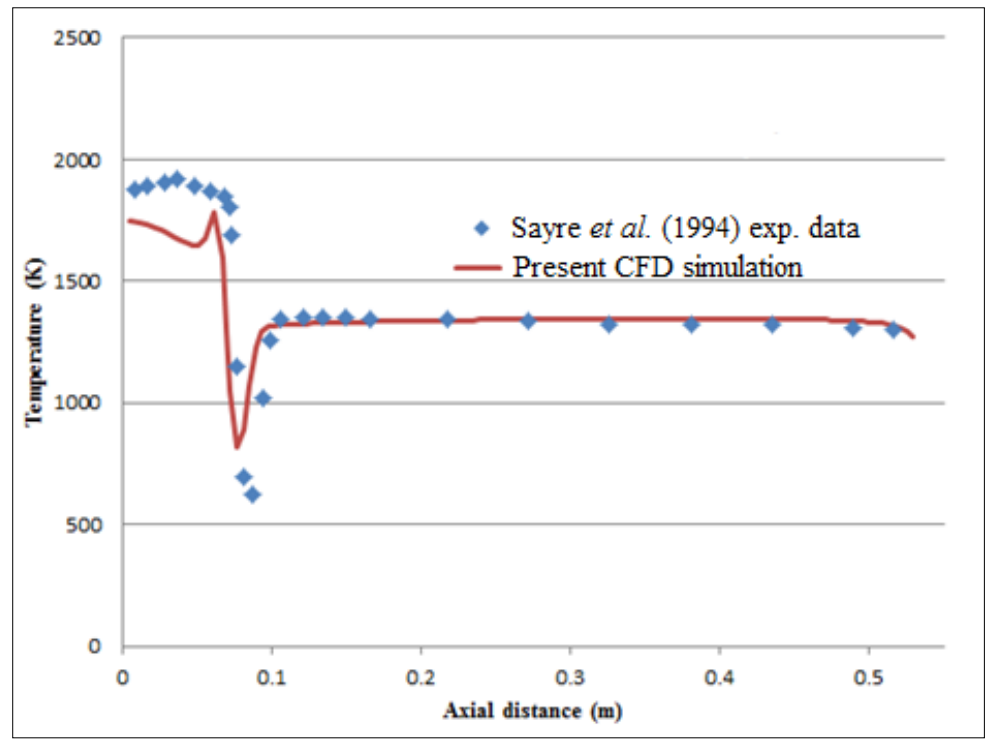

Figure 4.Variation of the furnace temperature along the axial distance at a location of $27 \mathrm{~mm}$ for comparison between steady-state 2DCFD computations with experiments analysis 
Validation of the finalized mesh, of size 80000, has been done by comparing the temperature distribution, as obtained by CFD, in the two-dimensional furnace at a location of $27 \mathrm{~mm}$ for steady-state turbulent combustion process with the experimental data of Sayre et al. (25) under similar boundary conditions. In experimental analysis, Sayre et al. (25) have chosen natural gas combustion with air. Radial temperature distribution at an axial location of $27 \mathrm{~mm}$ is considered for validation in this study. A plot of temperature distribution along the axial distance is shown in figure 4 . From the figure, it is clear that the match between the CFD and experimental results is in good agreement with a maximum deviation of about $6.3 \%$ by making the comparison of the maximum value of experimental data and computational data.

\section{RESULTS AND DISCUSSIONS}

For the analysis, two-dimensional steady-state pulverized coal combustion in the typical furnace has been simulated. The following six cases have been chosen for the parametric analysis of combustion of the pulverized coal of different composition (namely low volatiles, medium volatiles and high volatiles coal);

1. Top air velocity variation by keeping other boundary conditions constant.

2. Bottom air velocity variation by keeping other boundary conditions constant.

3. Air temperature variation by keeping other boundary conditions constant

4. Wall temperature variation by keeping other boundary conditions constant.

5. Mass flow rate variation of coal by keeping other boundary conditions constant.

6. Adiabatic wall boundary keeping other boundary conditions constant.

In all the above cases, location of coal injection, velocity of coal $(10 \mathrm{~m} / \mathrm{s}$ axial and $5 \mathrm{~m} / \mathrm{s}$ radial), particle size distribution, temperature at which coal is injected (300K), thermal conductivity $(0.025 \mathrm{~W} / \mathrm{m}-\mathrm{K})$, kinematic viscosity $\left(2 \times 10^{5} \mathrm{~kg} / \mathrm{m}-\mathrm{s}\right)$ of continuous phase are kept constant. Proximate and ultimate analysis of each type of coal is given in appendix-I along with the spatial discretization scheme chosen for all the simulations. Effect of variation of the above cases on the different parameters such as peak static temperature within the furnace (K), heat transfer rate $(\mathrm{kW})$ and emission of the different pollutants have been presented along the dimensionless length, at the outset. For all the cases, the values related to the low volatile coal has been taken as reference for considering the variation in the values of the parameters of other types of coal.

\section{Effect of top air velocity variation temperature and total heat transfer rate}

Two-dimensional steady-state simulated results of peak temperature inside the furnace and total heat transfer rate to/from the system for different top air velocities for different types of coal are shown in figure 5andfigure 6 . These are giving the plots of the effect of variation in top air velocity on the peak temperature and heat transfer rate respectively.

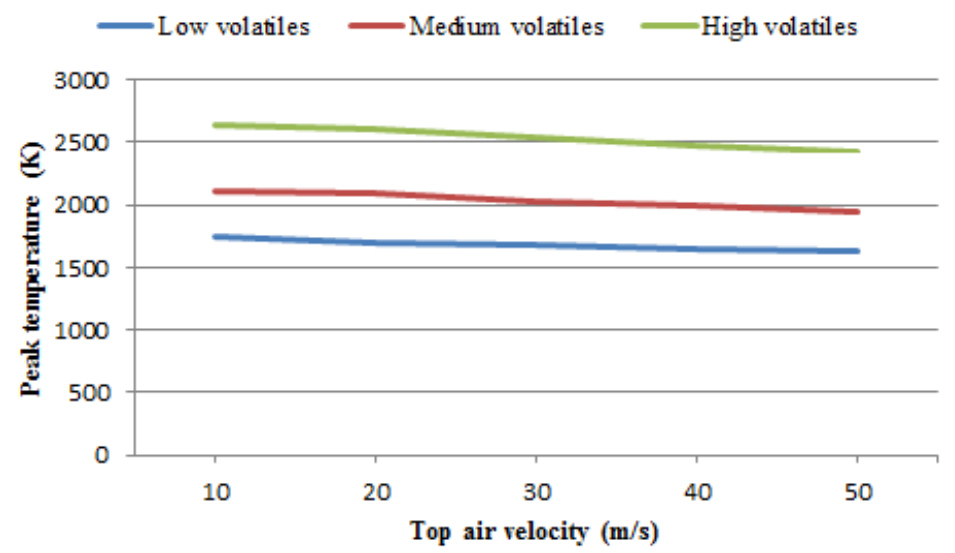

Figure 5. Variation of the peak furnace temperature with top air velocity for different types of coal 
Figure 5 presents that as top air velocity increases, peak temperature decreases for all types of volatiles. For the top air velocity of $10 \mathrm{~m} / \mathrm{s}$, there is an increase of $20.95 \%$ for medium volatiles and $51.42 \%$ for high volatiles coal at peak temperature. Whereas for $50 \mathrm{~m} / \mathrm{s}$, there is an increase of $18.86 \%$ for medium volatiles and $48.4 \%$ for high volatiles coal in peak temperature. Top air velocity, from $10 \mathrm{~m} / \mathrm{s}$ to $50 \mathrm{~m} / \mathrm{s}$, there is an overall drop of $6.07 \%$ for low volatiles, $7.83 \%$ for medium volatiles whereas about $7.95 \%$ for high volatiles coal in peak temperature.

From figure 6, as top air velocity increases, the heat transfer rate to the system decreases for low volatiles and medium volatiles whereas heat transfer decreases in case of high volatiles. For $10 \mathrm{~m} / \mathrm{s}$, there is a decrease of $30.31 \%$ for medium volatiles whereas there is a decrease of $135.41 \%$ for high volatiles coal (due to heat transferred to the surroundings) respectively. For $50 \mathrm{~m} / \mathrm{s}$, there is a decrease of about $8.15 \%$ for medium volatiles and $151.13 \%$ decrease for high volatiles coal respectively in heat transfer rate. For air velocity of $10 \mathrm{~m} / \mathrm{s}$ to $50 \mathrm{~m} / \mathrm{s}$, overall heat transfer rate is decreased by $39.29 \%$ for low volatiles coal, decreased by $16.85 \%$ for medium volatiles and $12.34 \%$ increase in high volatiles coal respectively.

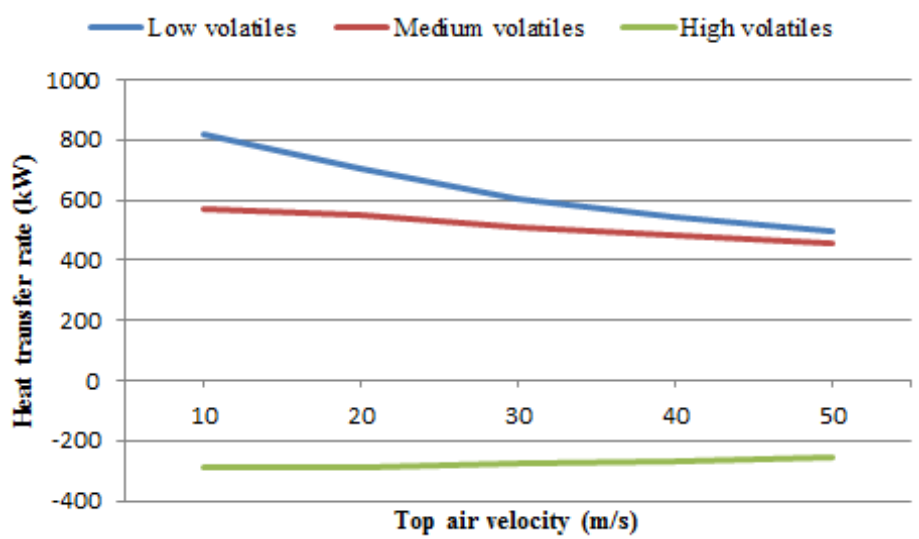

Figure 6.Variation of the furnace heat transfer rate with top air velocity for different types of coal

\section{Effect of top velocity variation on the emission of gases}

As far as $\mathrm{NOx}$ emission is concerned, the prompt $\mathrm{NO}_{\mathrm{x}}$, also known as transient nitrogen oxides, is formed due to the presence of carbon-containing radicals in the flames at low temperatures when nitrogen-containing fuel is burning. It is not taken into account because there is no relatively low-temperature zone inside the combustion chamber and it is found to be an order of $10^{-9}$ parts per million for all the simulations which can be negligible. Thermal $\mathrm{NO}_{\mathrm{x}}$ is formed when nitrogen and oxygen within the combustion gas combine relatively at high temperatures for a long time which is taken into account for analysis. Fuel $\mathrm{NO}_{\mathrm{x}}$, due to the presence of organic nitrogen in the coal is also taken into account of analysis. In all the graphs, NO represents nitrogen oxides. Emission of gases in parts per million for different bottom air velocities for different coal composition is shown in figures 7 - 9. For all the other types of parametric analysis, the same procedure is followed as for $\mathrm{NO}_{\mathrm{x}}$ emissions.

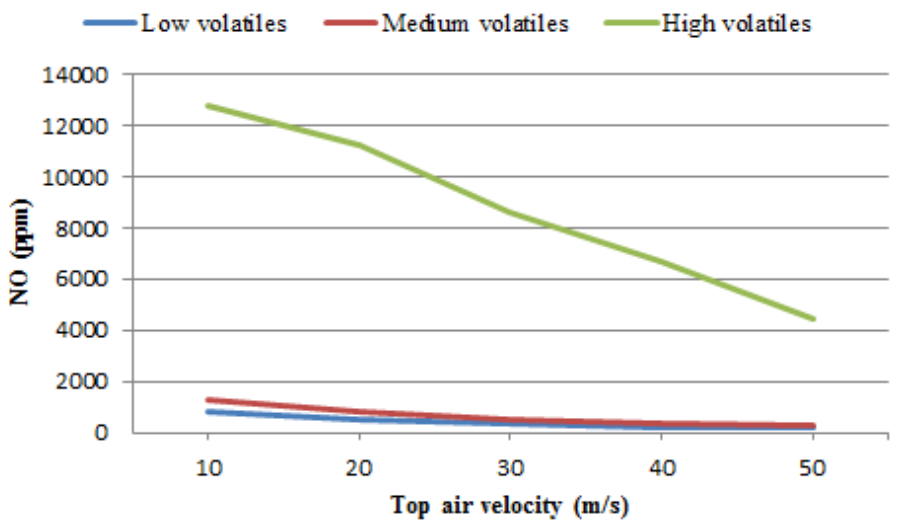

Figure 7. Effect of top air velocity on NO emission by the combustion of different types of coal 
From figure 7 it is observed that, as top air velocity increases, there is a decrease in compounds of NO emission in all the types of volatiles coal. For the top air velocity of $10 \mathrm{~m} / \mathrm{s}$, there is an increase of $61.57 \%$ in medium volatiles whereas an increase of $1481.54 \%$ for high volatiles coal in NO emission respectively. For the top air velocity of 50 $\mathrm{m} / \mathrm{s}$, there is an increase of $59.55 \%$ in medium volatiles whereas it is about $22.55 \%$ for high volatiles coal. For top air velocity from $10 \mathrm{~m} / \mathrm{s}$ to $50 \mathrm{~m} / \mathrm{s}$, there is an overall decrease of $76.45 \%$ for low volatiles, $76.74 \%$ for medium volatiles and $64.93 \%$ for high volatiles coal respectively.

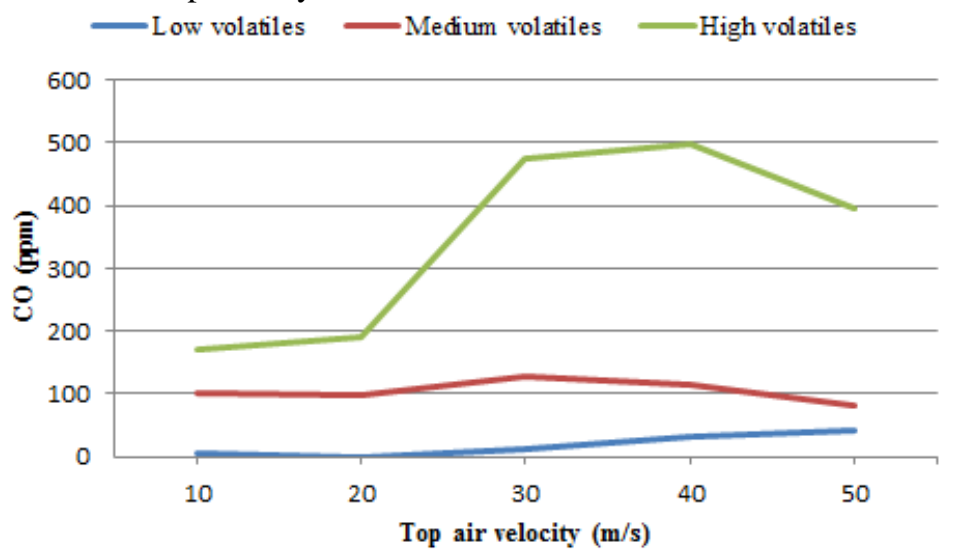

Figure 8. Effect of top air velocity on CO emission by the combustion of different types of coal

From figure 8, as top air velocity increases, for CO emission, a trend of increasing in low volatiles whereas increasing and then decreasing is observed in medium volatiles as well as high volatiles coal respectively. For the top air velocity of $10 \mathrm{~m} / \mathrm{s}$, there is an increase of $1445.06 \%$ in medium volatiles whereas an increase of $2501.81 \%$ for high volatiles coal. For the top air velocity of $50 \mathrm{~m} / \mathrm{s}$, there is an increase of $86.39 \%$ in medium volatiles whereas it is about $811.43 \%$ increase for high volatiles coal. For top air velocity from $10 \mathrm{~m} / \mathrm{s}$ to $50 \mathrm{~m} / \mathrm{s}$, there is an overall increase of $555.28 \%$ for low volatiles, a decrease of $20.95 \%$ for medium volatiles and an increase of $129.55 \%$ for high volatiles coal in $\mathrm{CO}$ emission respectively.

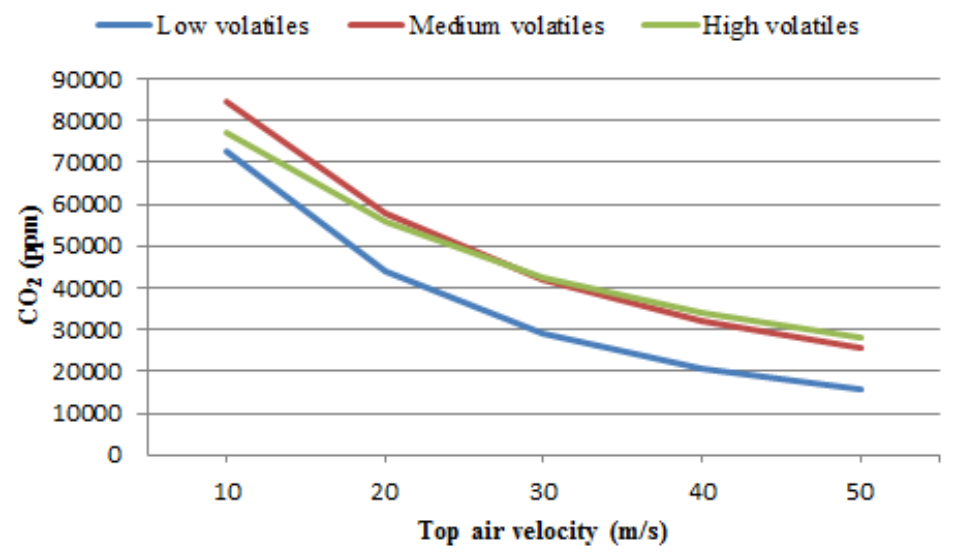

Figure 9. Effect of top air velocity on $\mathrm{CO}_{2}$ emission by the combustion of different types of coal

From figure 9, as top air velocity increases, for $\mathrm{CO}_{2}$ emission, a trend of decrease for all types of volatiles coal is observed respectively. Taking low volatiles as standard for comparison, for top air velocity of $10 \mathrm{~m} / \mathrm{s}$, there is an increase of $16.43 \%$ in medium volatiles whereas an increase of $6.34 \%$ for high volatiles coal is observed. For the top air velocity of $50 \mathrm{~m} / \mathrm{s}$, there is an increase of $59.44 \%$ in medium volatiles whereas it is about $75.62 \%$ increase for high volatiles coal is observed. For top air velocity from $10 \mathrm{~m} / \mathrm{s}$ to $50 \mathrm{~m} / \mathrm{s}$, there is an overall decrease of $78.05 \%$ for low volatiles, a decrease of $69.94 \%$ for medium volatiles and a decrease of $63.75 \%$ for high volatiles coal in $\mathrm{CO}_{2}$ emission is observed respectively. 


\section{Effect of bottom velocity variation on temperature and total heat transfer rate}

Figure 10 and figure 11 presents the results of peak temperature inside the furnace and total heat transfer rate to/from the system for different bottom air velocities for different types of coal. These were plotted asthe effect of the variation of the bottom air velocity on peak temperature and heat transfer rate, respectively.

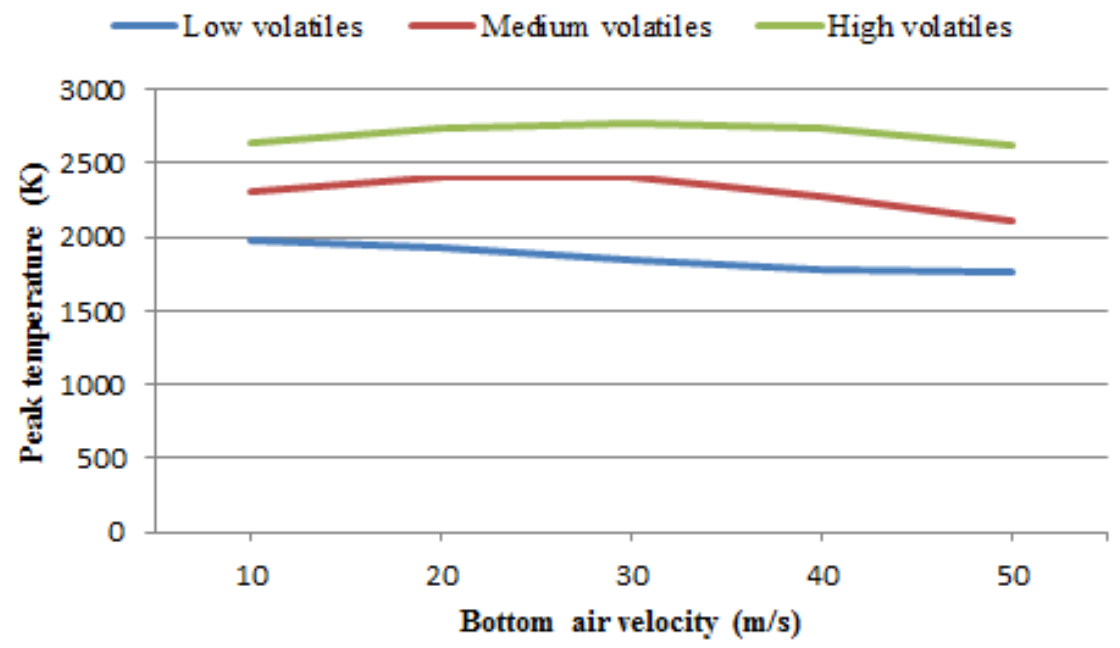

Figure 10. Variation of the peak furnace temperature with bottom air velocity for different types of coal

From figure 10, it is clear that as bottom air velocity increases, for low volatiles coal, the peak value of temperature inside the furnace decreases whereas for medium and high volatiles coal, it first increases and then decreases which breaks the usual mindset/assumption of increase of peak temperature. This fact is due to a certain velocity after which as velocity increases, the oxidizer coming inside the combustion chamber from the inlet will take away the coal particles with its speed resulting in not enough time for combustion to take place. It is also observed that as volatiles increases, the peak value of temperature also increases. This is due to the increase in the amount of volatiles, which participates in the combustion process. This means to source for the combustion also increases which results in high energy release during chemical reaction which is taking place between solid fuel (coal) and oxidizer (air), and thus bringing in the rise of temperature.

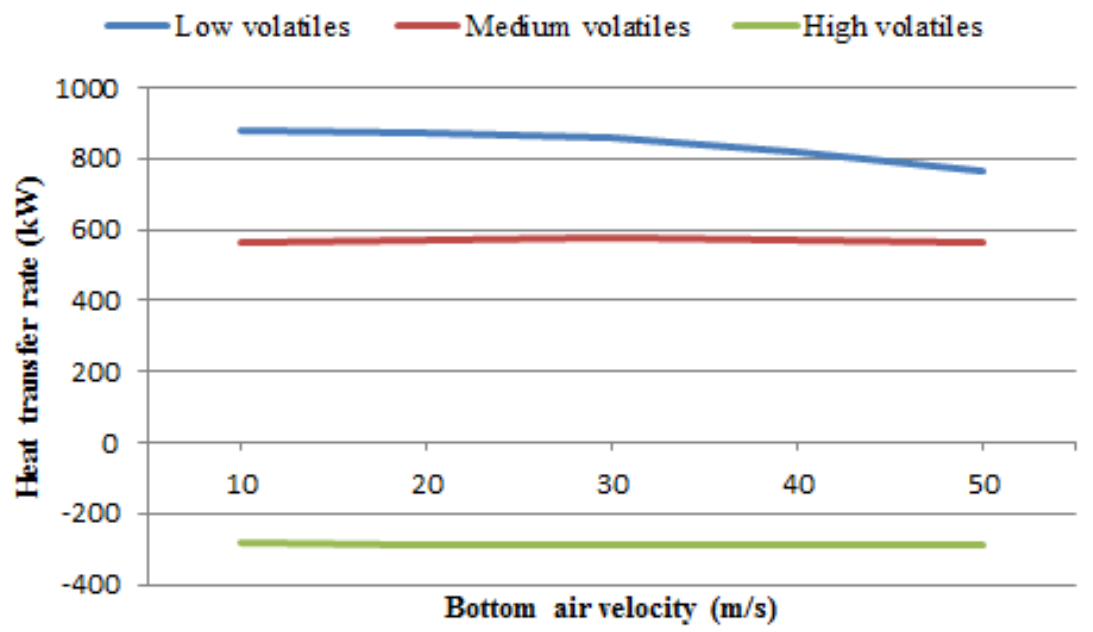

Figure 11. Variation of the furnace heat transfer rate with bottom air velocity for different types of coal 
From figure 11, it is clear that as bottom air velocity increases, heat transfer rate to the inlet boundaries decreases for low volatiles, first increases then decrease for medium volatiles whereas heat transfer (first increases then decreases) to the surroundings is more for high volatiles (positive value indicates heat transfer to the chamber through inlets whereas a negative value indicates heat transfer to the surroundings through top wall and outlet), which means for high volatiles that the energy released from chemical reactions is more contributing the heat loss to the surroundings.

\section{Effect of bottom velocity variation on the emission of gases}

The emission of gases in parts per million for different bottom air velocities for different coal composition is shown in Figure 12, Figure 13 and Figure 14.

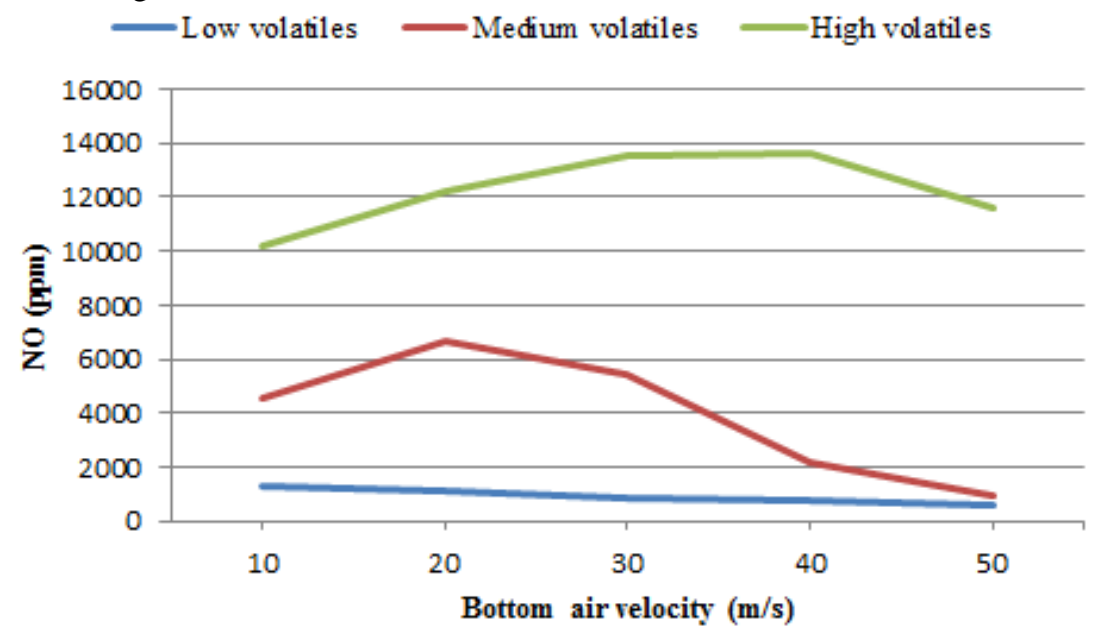

Figure 12. Effect of bottom air velocity on NO emission by the combustion of different types of coal

From figure 12 it is clear that, as bottom air velocity increases, emission of nitrogen oxides are more as volatile composition increases. It is also observed that nitrogen oxide emission for medium volatiles and high volatiles coals first increases and then decreases whereas for low volatiles coal decreases. The decreased portion is because as velocity increases, the velocity of high-temperature flue gas is so quick that there is insufficient time to generate $\mathrm{NO}_{\mathrm{x}}$ inside the chamber. Also, there is much difference between the value of $\mathrm{NO}(\mathrm{ppm})$ release for medium volatiles and high volatiles (as obvious from the plots) which is giving a clue that as volatiles increases incomplete combustion is more for different bottom air velocities.

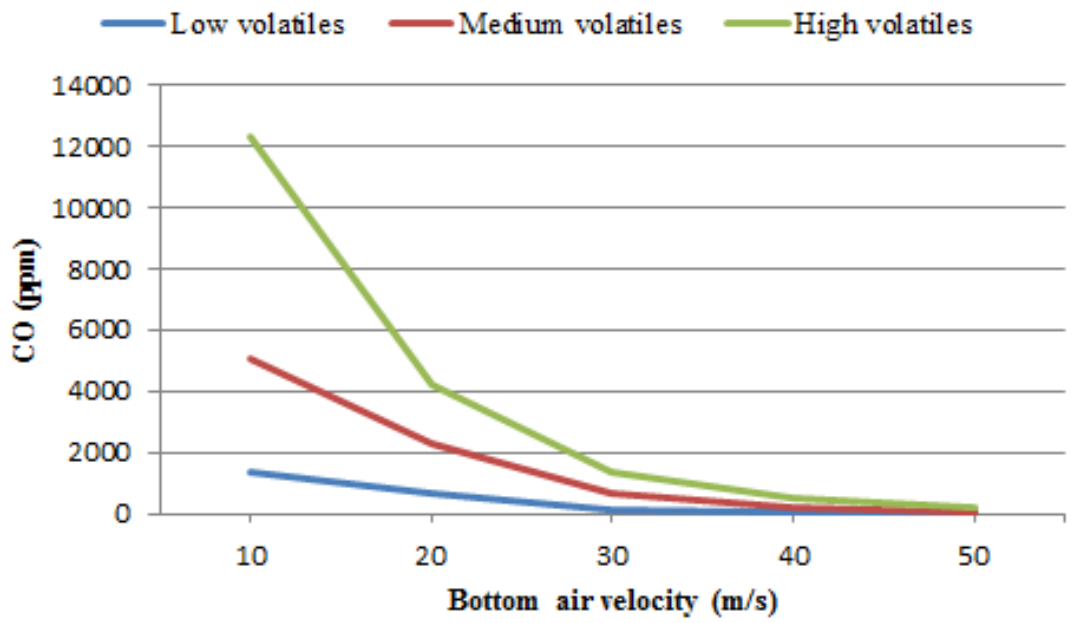

Figure 13. Effect of bottom air velocity on CO emission by the combustion of different types of coal 
Figure 13 presents that as bottom air velocity increases, $\mathrm{CO}$ emission decreases for all types of volatiles which indicate that a situation of complete combustion can be achieved although in general incomplete combustion is major in all types of combustion chambers. It is also observed that there is a sudden drop of about $8000 \mathrm{CO}$ ppm emission for the bottom velocity of 10 to $20 \mathrm{~m} / \mathrm{s}$ indicating the essential requirement of oxidizer for the combustion process.

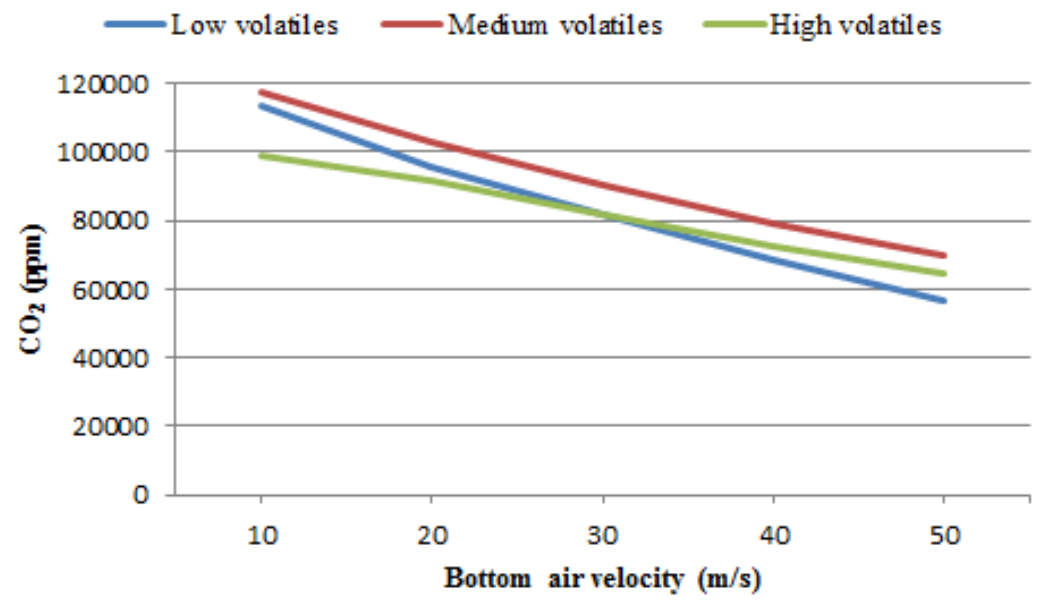

Figure 14. Effect of bottom air velocity on $\mathrm{CO}_{2}$ emission by the combustion of different types of coal

From figure 14 it is understood that as bottom air velocity increases, for $\mathrm{CO}_{2}$ emission, a trend of decrease for all three types of coal is observed. Taking low volatiles as standard for comparison, for bottom air velocity of $10 \mathrm{~m} / \mathrm{s}$, there is an increase of $3.01 \%$ in medium volatiles whereas a decrease of $12.77 \%$ for high volatiles coal is observed. For the bottom air velocity of $50 \mathrm{~m} / \mathrm{s}$, there is an increase of $22.85 \%$ in medium volatiles whereas it is about $14.48 \%$ increase for high volatiles coal is observed. For bottom air velocity from $10 \mathrm{~m} / \mathrm{s}$ to $50 \mathrm{~m} / \mathrm{s}$, there is an overall decrease of $50.22 \%$ for low volatiles, a decrease of $40.64 \%$ for medium volatiles and a decrease of $34.67 \%$ for high volatiles coal in $\mathrm{CO}_{2}$ emission is observed respectively.

\section{Effect of air temperature variation on peak temperature and total heat transfer rate}

The effect of the air temperature variation on the peak temperature inside the furnace and total heat transfer rate to/from the system for different air temperatures for different types of coal are shown in figure 15 and figure 16, respectively.

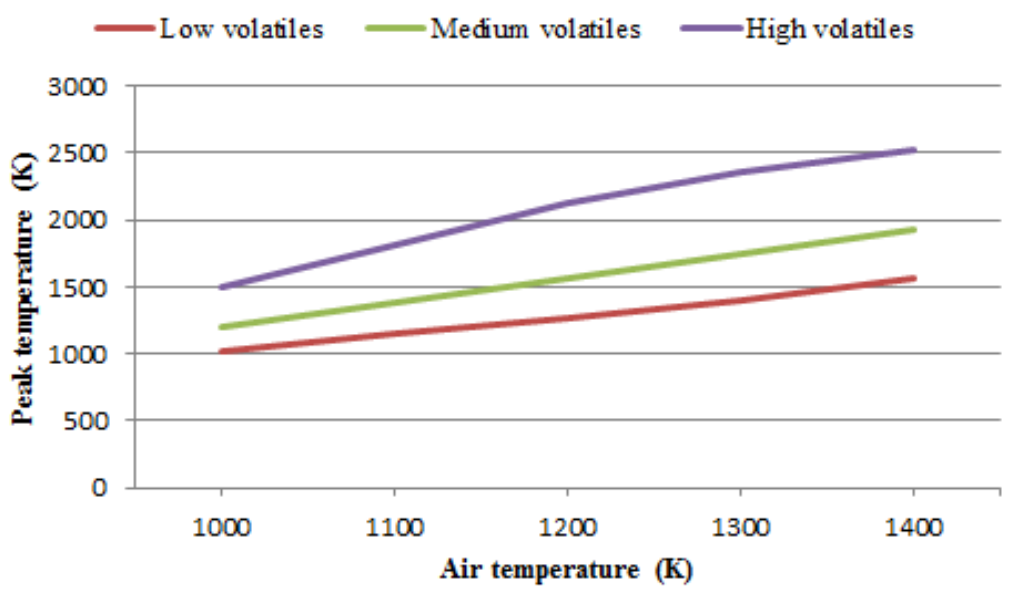

Figure 15. Variation of the peak furnace temperature with bottom air temperature for different types of coal 
From figure 15 it is understood that, as air temperature increases, peak temperature increases for all types of volatiles. Taking low volatiles plot as reference for comparison purpose, for an air temperature of $1000 \mathrm{~K}$, there is an increase of $16.21 \%$ for medium volatiles and $46.42 \%$ for high volatiles coal in peak temperature. Whereas for $1400 \mathrm{~K}$, there is an increase of $22.99 \%$ for medium volatiles and $60.34 \%$ for high volatiles coal at peak temperature. Air temperature, from $1000 \mathrm{~K}$ to $1400 \mathrm{~K}$, there is an overall increase of $52.7 \%$ for low volatiles, $61.61 \%$ for medium volatiles whereas about $67.22 \%$ for high volatiles coal in peak temperature.

From figure 16 it is concluded that as the air temperature increases, heat transfer rate to the system increases for low volatiles and medium volatiles whereas heat transfer to the surroundings increases in case of high volatiles. Taking low volatiles coal as standard for comparison, for an air temperature of $1000 \mathrm{~K}$, there is an increase of $43.34 \%$ for medium volatiles whereas there is a decrease of $187.64 \%$ for high volatiles coal (due to heat transferred to the surroundings) respectively. For air temperature of $1400 \mathrm{~K}$, there is a decrease of about $15.8 \%$ for medium volatiles and $146.76 \%$ decrease for high volatiles coal respectively in heat transfer rate. Air temperature, from $1000 \mathrm{~K}$ to $1400 \mathrm{~K}$, an overall heat transfer rate is increased by $241.99 \%$ for low volatiles coal, increased by $100.89 \%$ for medium volatiles and $82.48 \%$ increase in high volatiles coal.

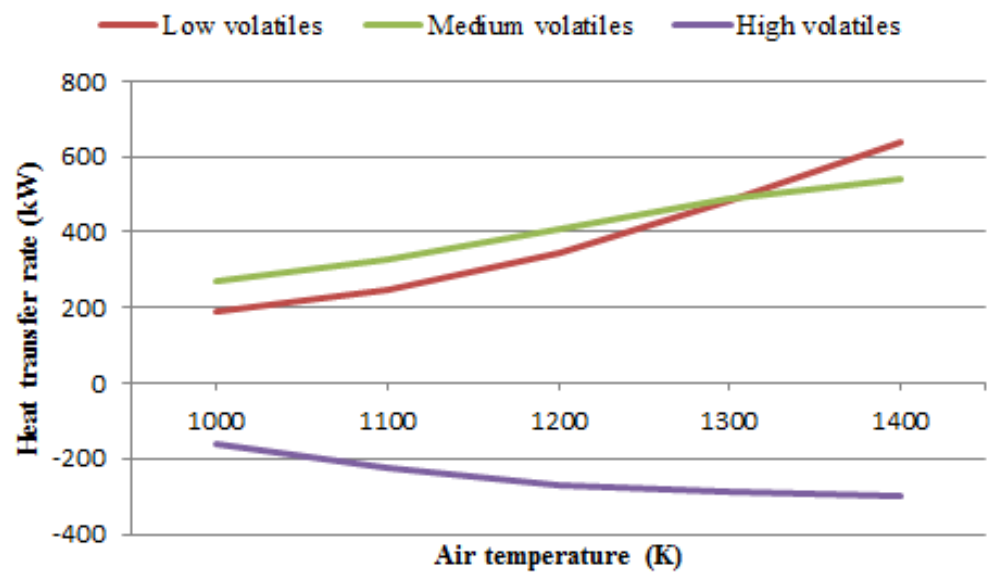

Figure 16. Variation of the furnace heat transfer rate with bottom air temperature for different types of coal

\section{Effect of air temperature variation on the emission of gases}

Emission of gases in parts per million for different bottom air temperature for different coal composition are in figure 17, figure 18 and figure 19.

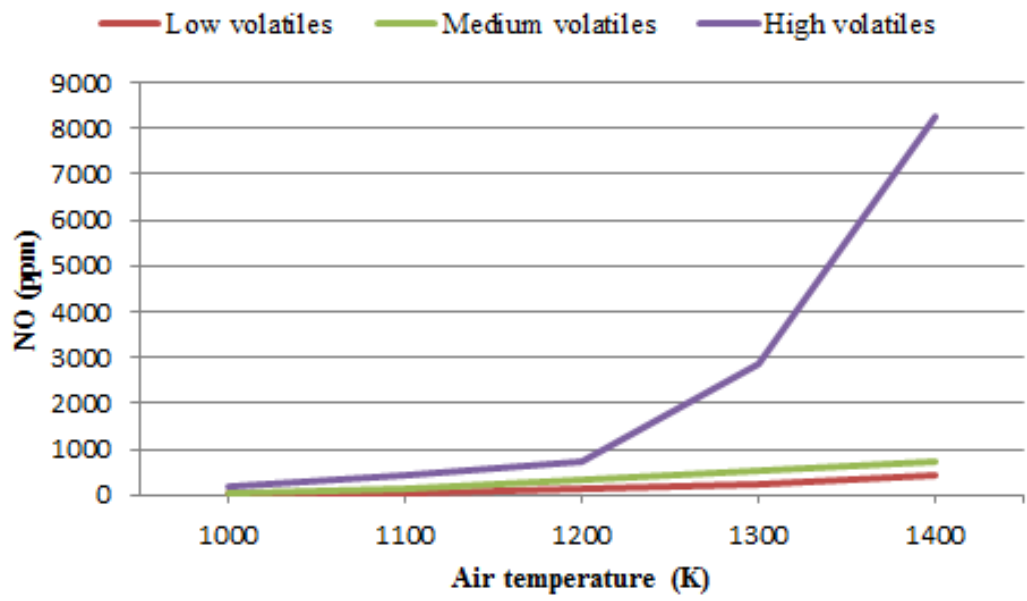

Figure 17. Effect of bottom air temperature on NO emission by the combustion of different types of coal 
From figure 17 it is understood that as air temperature increases, there is an increase in compounds of NO emission in all the types of volatiles coal. Taking low volatiles as reference for comparison, for an air temperature of $1000 \mathrm{~K}$, there is an increase of $177.74 \%$ in medium volatiles whereas an increase of $755.51 \%$ for high volatiles coal in NO emission respectively. For air temperature of $1400 \mathrm{~K}$, there is an increase of $65.56 \%$ in medium volatiles whereas it is about $1795.55 \%$ increase for high volatiles coal. Air temperature, from $1000 \mathrm{~K}$ to $1400 \mathrm{~K}$, there is an overall increase of $1970.09 \%$ for low volatiles, $1133.97 \%$ for medium volatiles and $4486.72 \%$ for high volatiles coal respectively. The volatile matter in coal is an indication of gaseous fuels and incombustible gases (carbon dioxide and nitrogen) presence. Thus, during the combustion emission of NO is highest in high volatile coal. Moreover, as the temperature increases the rate of emission of nitrogen gases increases and gets oxidized to form more NO.

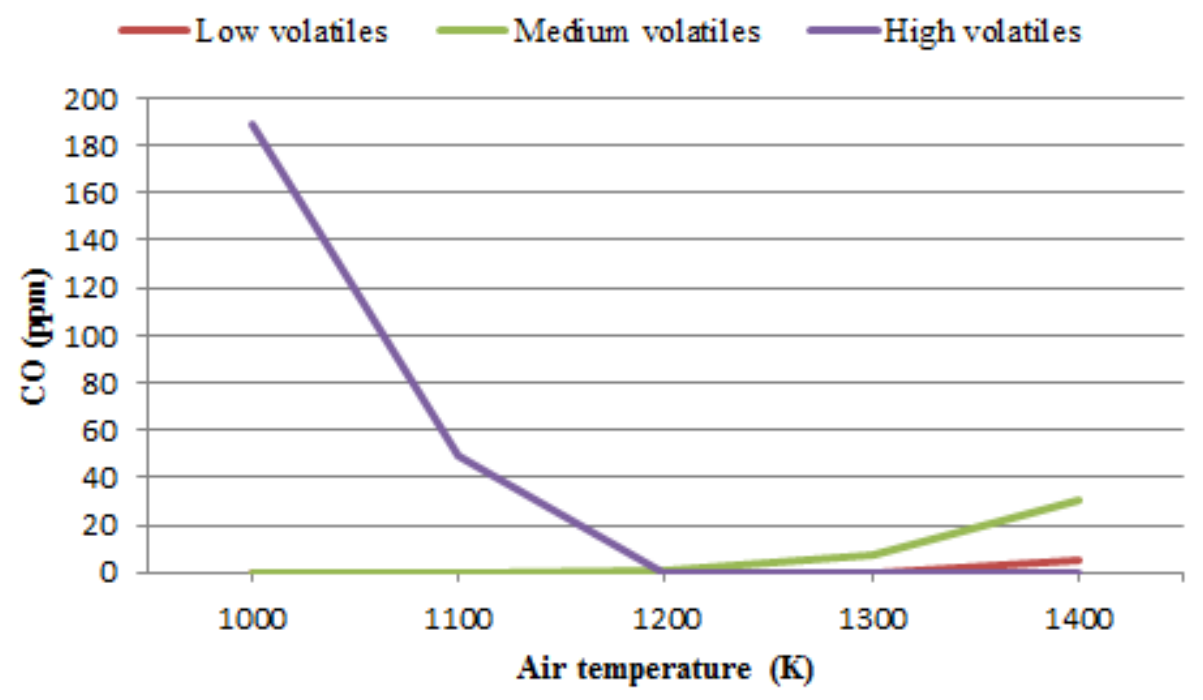

Figure 18. Effect of bottom air temperature on $\mathrm{CO}$ emission by the combustion of different types of coal

From figure 18, as air temperature increases, for CO emission, a trend of increasing in low volatiles, medium volatiles whereas a trend of decrease in high volatiles coal is observed. At an air temperature of $1000 \mathrm{~K}$, CO emission for low volatiles coal is zero which means that entire carbon in coal is converted to $\mathrm{CO}_{2}$ (also $\mathrm{CO}$ emission zero means that complete reduction in one of the harmful gases under stated conditions) irrespective of ash containing carbon, $0.028 \mathrm{ppm}$ for medium volatiles coal and $188.947 \mathrm{ppm}$ for high volatiles coal. At an air temperature of $1400 \mathrm{~K}$, medium volatiles coal is about $498.81 \%$ more in CO emission as compared to low volatiles coal.

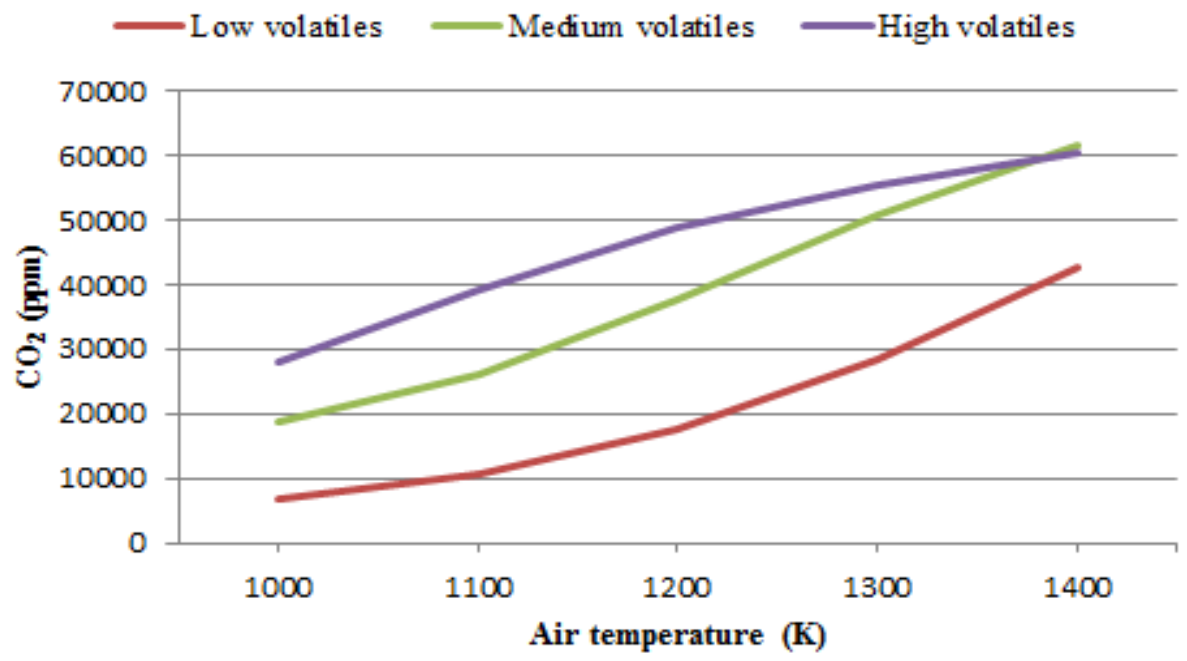

Figure 19. Effect of bottom air temperature on $\mathrm{CO}_{2}$ emission by the combustion of different types of coal 
From figure 19, as air temperature increases, for $\mathrm{CO}_{2}$ emission, a trend of increasing in all types of volatiles coal is observed. Taking low volatiles as standard for comparison, for an air temperature of $1000 \mathrm{~K}$, there is an increase of $172.68 \%$ in medium volatiles whereas an increase of $310.56 \%$ for high volatiles coal is observed. For air temperature of $1400 \mathrm{~K}$, there is an increase of $43.74 \%$ in medium volatiles whereas it is about $41.40 \%$ increase for high volatiles coal is observed. For air temperature from $1000 \mathrm{~K}$ to $1400 \mathrm{~K}$, there is an overall increase of $527.58 \%$ for low volatiles, a decrease of $230.60 \%$ for medium volatiles and an increase of $116.17 \%$ for high volatiles coal in $\mathrm{CO}_{2}$ emission is observed.

\section{Effect of wall temperature variation on temperature and total heat transfer rate}

Effect of the furnace wall temperature variation on peak temperature inside the furnace and total heat transfer rate to/from the system for different air temperatures for different types of coal are shown in figure 20 and figure 21.

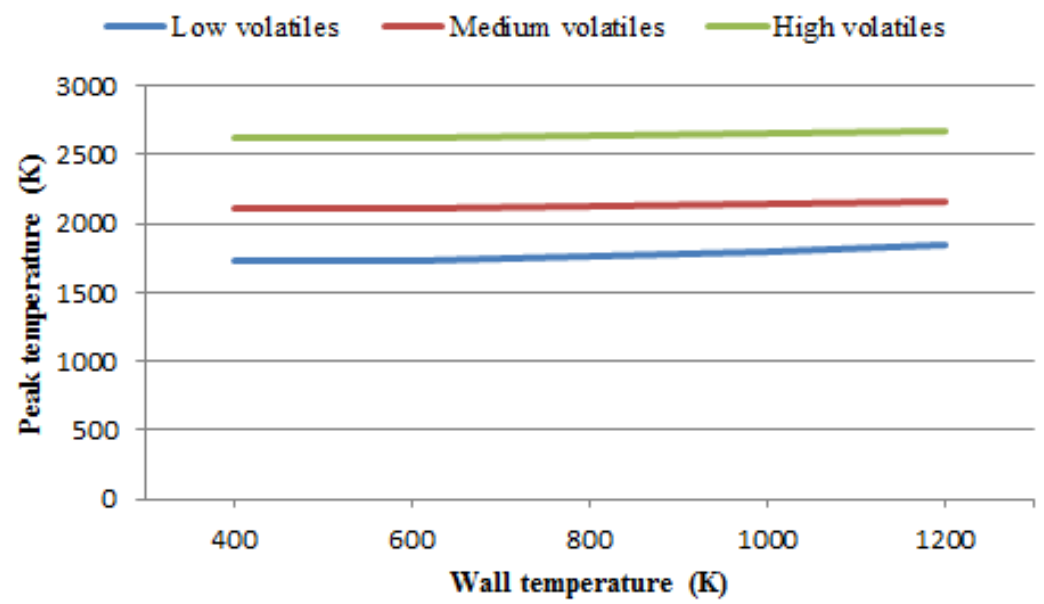

Figure 20. Variation of the peak furnace temperature with furnace wall temperature for different types of coal

From figure 20, as wall temperature increases, peak temperature increases for all types of volatiles. Taking low volatiles plot as standard for comparison, for wall temperature of $400 \mathrm{~K}$, there is an increase of $22.26 \%$ for medium volatiles and $52.52 \%$ for high volatiles coal in peak temperature. Whereas for $1200 \mathrm{~K}$, there is an increase of $16.75 \%$ for medium volatiles and $44.02 \%$ for high volatiles coal at peak temperature. Wall temperature, from $400 \mathrm{~K}$ to 1200 $\mathrm{K}$, there is an overall increase of $7.40 \%$ for low volatiles, $2.56 \%$ for medium volatiles, and $1.42 \%$ for high volatiles coal at peak temperature.

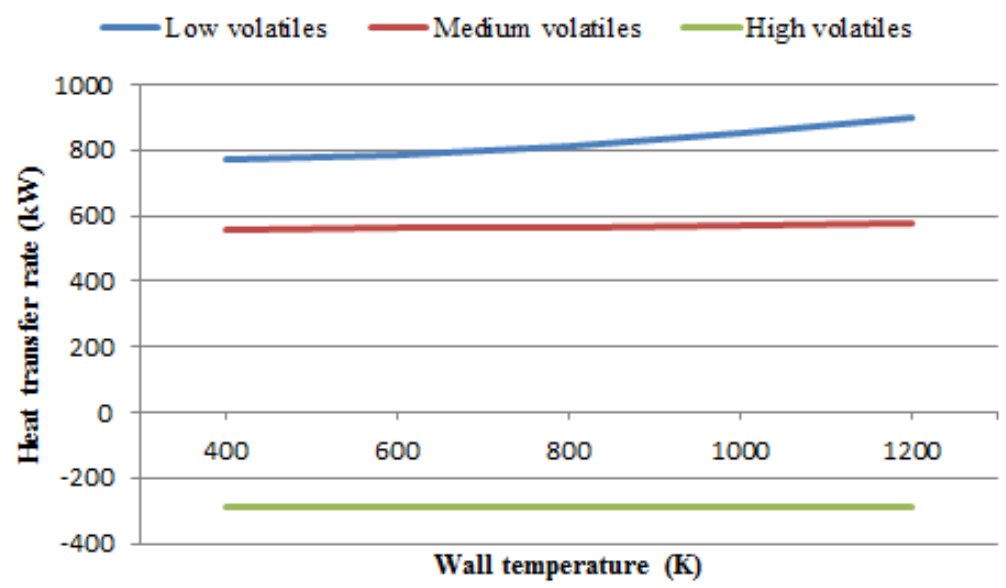

Figure 21. Variation of the furnace heat transfer rate with furnace wall temperature for different types of coal 
From figure 21, as wall temperature increases, heat transfer rate to the system is increased for low volatiles and medium volatiles whereas heat transfer to the surroundings increases slightly in case of high volatiles. Taking low volatiles coal as standard for comparison, for wall temperature of $400 \mathrm{~K}$, there is a decrease of $27.35 \%$ for medium volatiles whereas there is a decrease of $137.70 \%$ for high volatiles coal (due to heat transferred to the surroundings) respectively. For the wall temperature of $1200 \mathrm{~K}$, there is a decrease of about $35.78 \%$ for medium volatiles and $132.38 \%$ decrease for high volatiles coal respectively in heat transfer rate. Wall temperature, from $400 \mathrm{~K}$ to $1200 \mathrm{~K}$, an overall heat transfer rate is increased by $16.56 \%$ for low volatiles coal, increased by $2.89 \%$ for medium volatiles and $0.09 \%$ increase in high volatiles coal.

\section{Effect of wall temperature variation on the emission of gases}

Emission of gases in parts per million for variation of furnace wall temperature for different coal composition is shown in figure 22, figure 23 and figure 24.

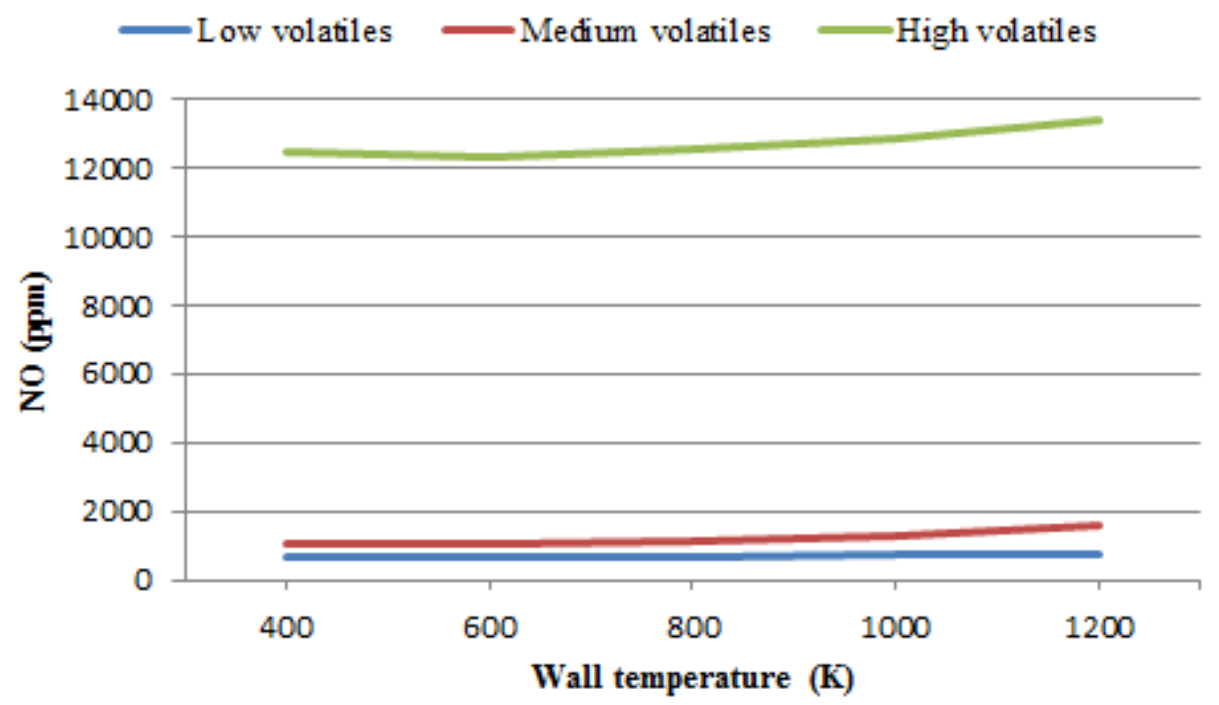

Figure 22. Effect of furnace wall temperature on NO emission by the combustion of different types of coal

From figure 22, as wall temperature increases, there is an increase in compounds of NO emission in all the types of volatiles coal. Taking low volatiles as standard for comparison, for wall temperature of $400 \mathrm{~K}$, there is an increase of $63.93 \%$ in medium volatiles whereas an increase of $1840.91 \%$ for high volatiles coal in NO emission respectively. For the wall temperature of $1200 \mathrm{~K}$, there is an increase of $10.15 \%$ in medium volatiles whereas it is about $1626.88 \%$ increase for high volatiles coal. Wall temperature, from $400 \mathrm{~K}$ to $1200 \mathrm{~K}$, there is an overall increase of $21.06 \%$ for low volatiles, $48.78 \%$ for medium volatiles and $7.71 \%$ for high volatiles coal respectively. '

From figure 23, as wall temperature increases, for $\mathrm{CO}$ emission, a trend of increasing in all types of volatile coal is observed. At the wall temperature of $400 \mathrm{~K}$, CO emission for low volatile coal is zero which means that entire carbon in coal is converted to $\mathrm{CO}_{2}$ irrespective of ash containing carbon and there is an increase of $46.21 \%$ for high volatiles coal as compared to medium volatile coal. At the wall temperature of $1200 \mathrm{~K}$, medium volatiles coal is about $183.26 \%$ and high volatiles coal $438.84 \%$ more in CO emission as compared to low volatiles coal. Wall temperature, from $400 \mathrm{~K}$ to $1200 \mathrm{~K}$, an overall increase of $136.83 \%$ for medium volatiles and $208.12 \%$ for high volatiles in $\mathrm{CO}$ emission is observed. 
Journal of Thermal Engineering, Research Article, Vol. 6, No. 6, Special Issue 12, pp. 323-353,

December, 2020

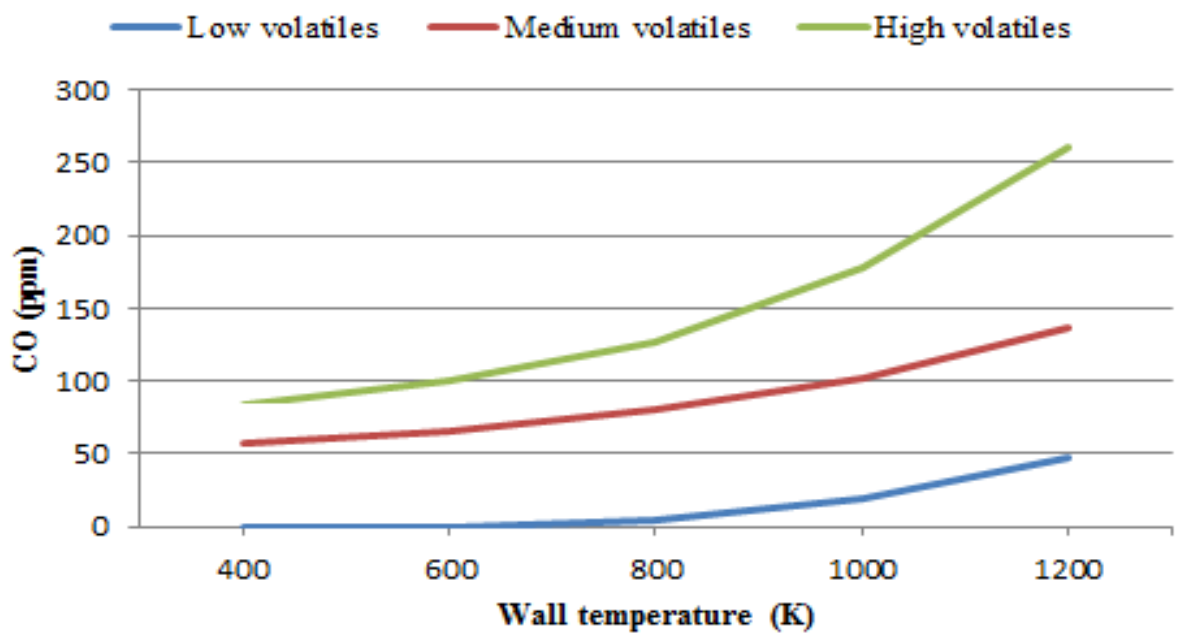

Figure 23. Effect of furnace wall temperature on CO emission by the combustion of different types of coal

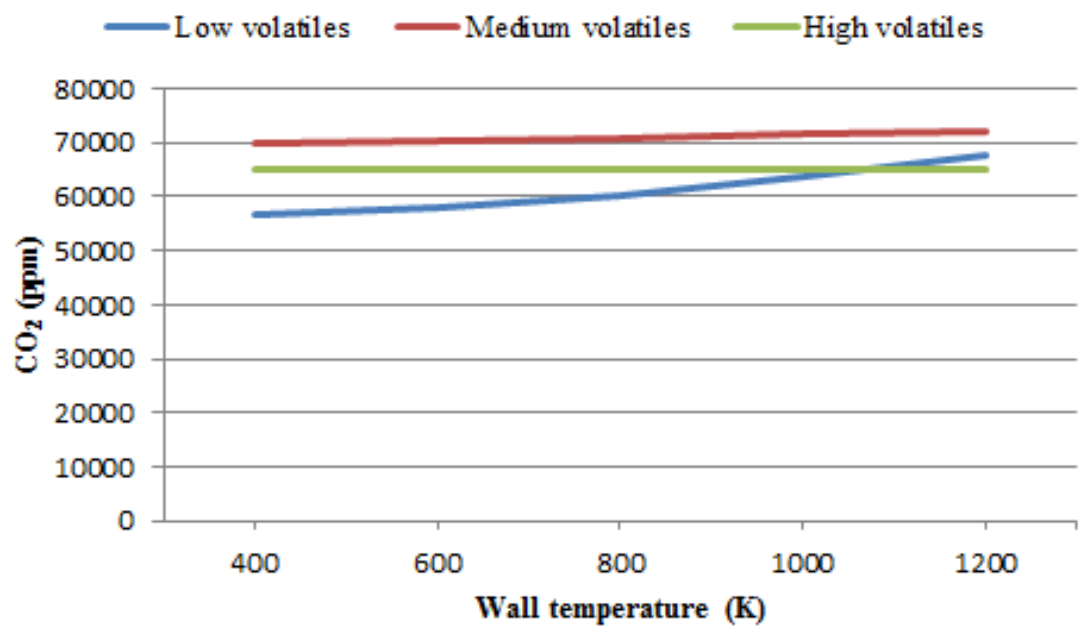

Figure 24. Effect of furnace wall temperature on $\mathrm{CO}_{2}$ emission by the combustion of different types of coal

From figure 24, as wall temperature increases, for $\mathrm{CO}_{2}$ emission, a trend of increasing in all types of volatiles coal is observed. Taking low volatiles as standard for comparison, for wall temperature of $400 \mathrm{~K}$, there is an increase of $23.06 \%$ in medium volatiles whereas an increase of $14.75 \%$ for high volatiles coal is observed. For the wall temperature of $1200 \mathrm{~K}$, there is an increase of $7.00 \%$ in medium volatiles whereas it is about a $3.75 \%$ increase for high volatiles coal is observed. Wall temperature, from $400 \mathrm{~K}$ to $1200 \mathrm{~K}$, there is an overall increase of $19.11 \%$ for low volatiles, an increase of $3.57 \%$ for medium volatiles and an increase of $0.09 \%$ for high volatiles coal in $\mathrm{CO}_{2}$ emission is observed.

\section{Effect of coal mass flow rate variation on temperature and total heat transfer rate}

2D steady-state simulated results of peak temperature inside the furnace and total heat transfer rate to/from the system for different coal mass flow rates for different types of coal are shown in figure 25 and figure 26. 
Journal of Thermal Engineering, Research Article, Vol. 6, No. 6, Special Issue 12, pp. 323-353, December, 2020

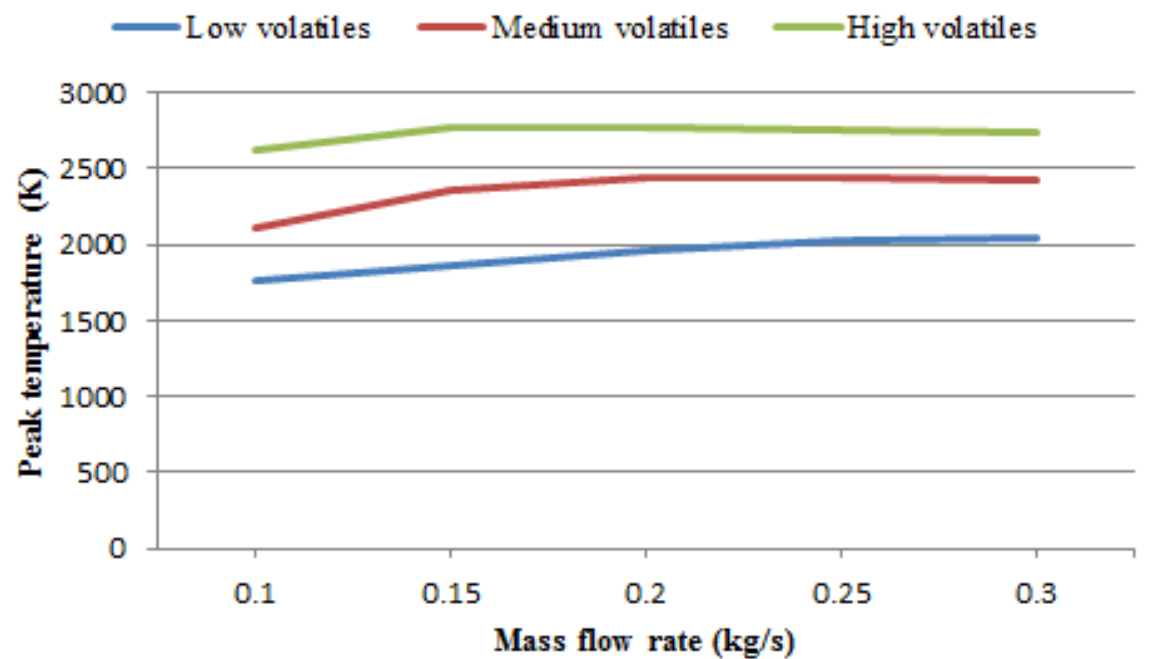

Figure 25. Variation of the peak furnace temperature with coal mass flow rate for different types of coal

From figure 25, as mass flow rate increases, peak temperature increases for all types of volatiles. Taking low volatiles plot as standard for comparison, for the mass flow rate of $0.1 \mathrm{~kg} / \mathrm{s}$, there is an increase of $19.34 \%$ for medium volatiles and $48.72 \%$ for high volatiles coal in peak temperature. Whereas for $0.3 \mathrm{~kg} / \mathrm{s}$, there is an increase of $18.25 \%$ for medium volatiles and $33.61 \%$ for high volatiles coal at peak temperature. Coal mass flow rate, from $0.1 \mathrm{~kg} / \mathrm{s}$ to 0.3 $\mathrm{kg} / \mathrm{s}$, there is an overall increase of $16.35 \%$ for low volatiles, $15.29 \%$ for medium volatiles and $4.54 \%$ for high volatiles coal in peak temperature.

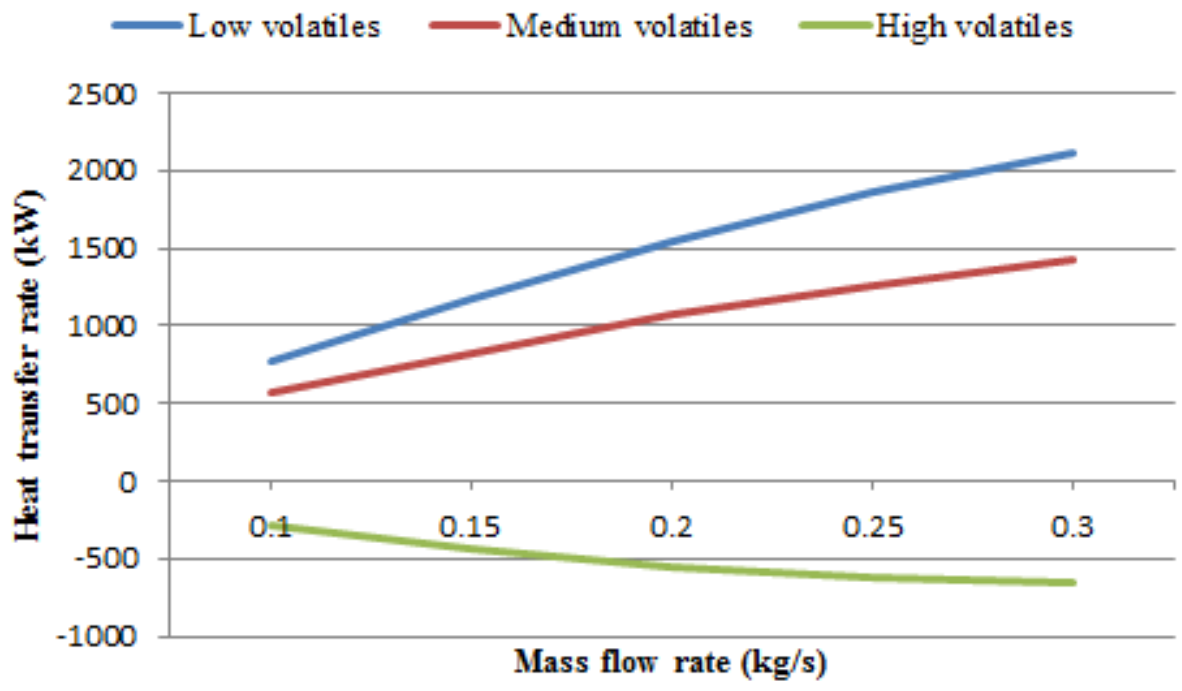

Figure 26. Variation of the furnace heat transfer rate with coal mass flow rate for different types of coal

From figure 26, as coal mass flow rate increases, heat transfer rate to the system increases for low volatiles and medium volatiles whereas heat transfer to the surroundings increases in case of high volatiles. Taking low volatiles coal as standard for comparison, for mass flow of $0.1 \mathrm{~kg} / \mathrm{s}$, there is a decrease of $26.69 \%$ for medium volatiles whereas there is a decrease of $137.85 \%$ for high volatiles coal (due to heat transferred to the surroundings) respectively. For the mass flow rate of $0.3 \mathrm{~kg} / \mathrm{s}$, there is a decrease of about $32.84 \%$ for medium volatiles and $131.27 \%$ decrease for high volatiles coal respectively in heat transfer rate. Coal mass flow rate, from $0.1 \mathrm{~kg} / \mathrm{s}$ to $0.3 \mathrm{~kg} / \mathrm{s}$, an overall heat transfer rate is increased by $175.74 \%$ for low volatiles coal, increased by $152.59 \%$ for medium volatiles and $127.78 \%$ increase in high volatiles coal. 


\section{Effect of coal mass flow rate variation on the emission of gases}

Emission of gases in parts per million for different coal mass flow rate for different coal composition is shown in figure 27, figure 28 and figure 29.

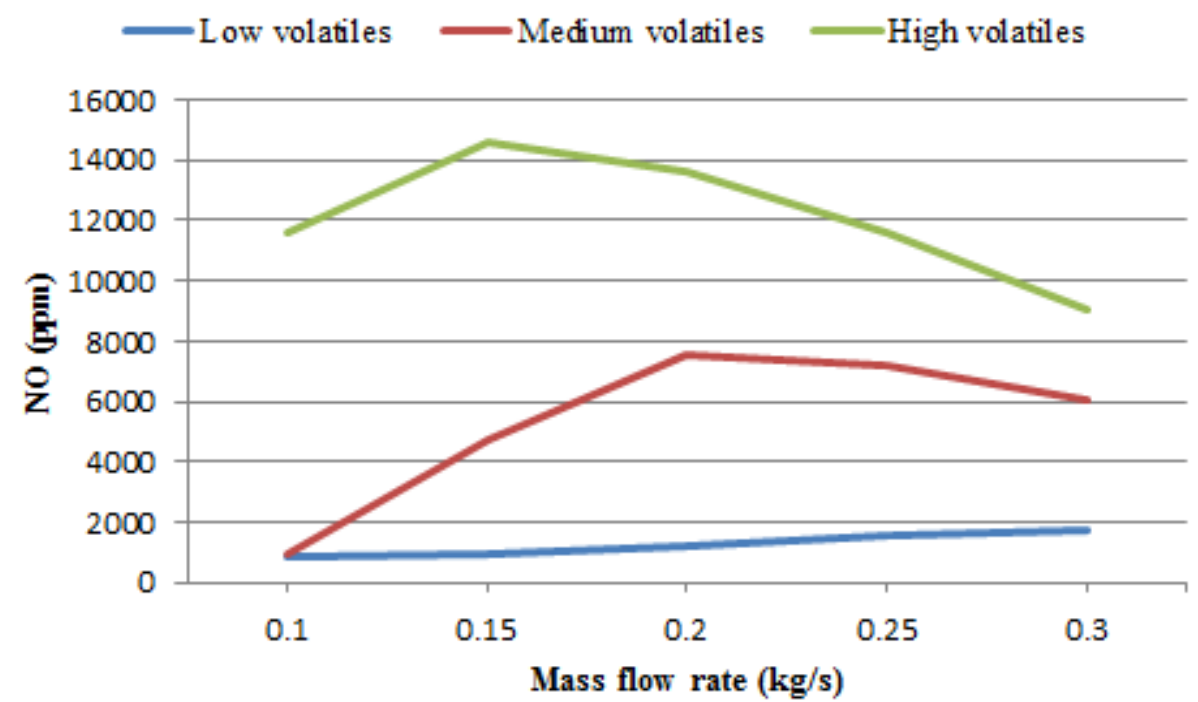

Figure 27. Effect of coal mass flow rate on NO emission by the combustion of different types of coal

From figure 27, as mass flow rate increases, there is an increase in compounds of NO emission in low volatiles coal whereas increasing and decreasing trend is observed in medium volatiles and high volatiles coal respectively. The peak in NO emission is observed at $0.15 \mathrm{~kg} / \mathrm{s}$ for high volatiles and $0.2 \mathrm{~kg} / \mathrm{s}$ for medium volatiles coal. Taking low volatiles as standard for comparison, for coal mass flow rate of $0.1 \mathrm{~kg} / \mathrm{s}$, there is an increase of $54.71 \%$ in medium volatiles whereas an increase of $1721.56 \%$ for high volatiles coal in NO emission respectively. For the mass flow rate of $0.3 \mathrm{~kg} / \mathrm{s}$, there is an increase of $257.78 \%$ in medium volatiles whereas it is about $432.40 \%$ increase for high volatiles coal. Coal mass flow rate, from $0.1 \mathrm{~kg} / \mathrm{s}$ to $0.3 \mathrm{~kg} / \mathrm{s}$, there is an overall increase of $167.22 \%$ for low volatiles, $517.98 \%$ for medium volatiles and decrease of $21.90 \%$ for high volatiles coal respectively.

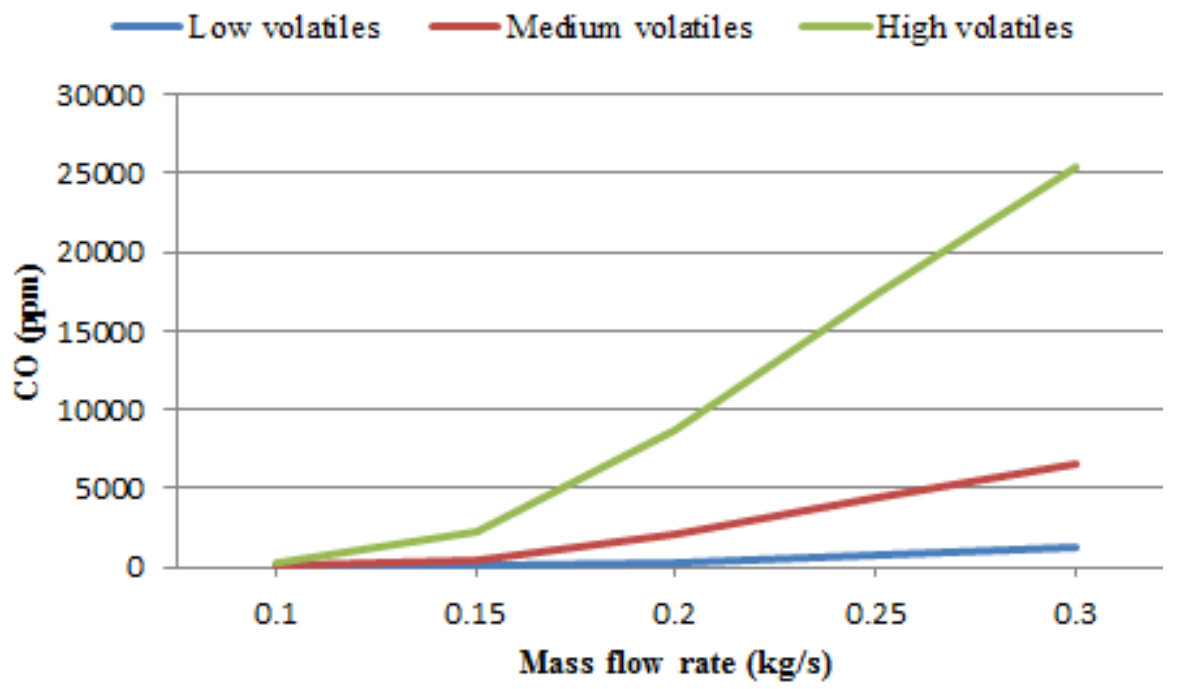

Figure 28. Effect of coal mass flow rate on $\mathrm{CO}$ emission by the combustion of different types of coal

From figure 28, as coal mass flow rate increases, for CO emission, a trend of increasing in all types of volatile coal is observed. Taking low volatiles coal as a base for comparison, for coal mass flow rate of $0.1 \mathrm{~kg} / \mathrm{s}$, there is an increase of $279.83 \%$ for medium volatiles and $1046.54 \%$ for high volatiles coal in NO emission respectively. For the 
mass flow rate of $0.3 \mathrm{~kg} / \mathrm{s}$, medium volatiles coal is about $419.01 \%$ and high volatiles coal $1886.41 \%$ increase in CO emission as compared to low volatiles coal. Coal mass flow rate, from $0.1 \mathrm{~kg} / \mathrm{s}$ to $0.3 \mathrm{~kg} / \mathrm{s}$, an overall increase of $6130.64 \%$ for low volatiles, $8413.77 \%$ for medium volatiles and $10694.70 \%$ for high volatiles in CO emission is observed.

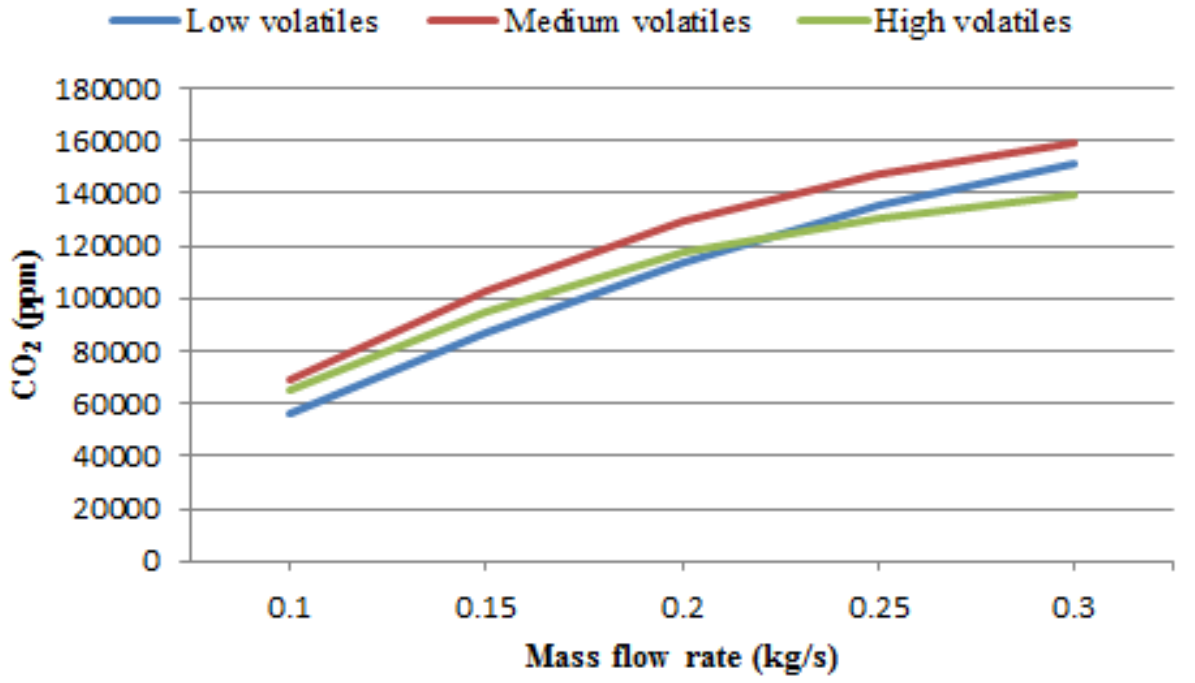

Figure 29. Effect of coal mass flow rate on $\mathrm{CO}_{2}$ emission by the combustion of different types of coal

From figure 29, as coal mass flow rate increases, for $\mathrm{CO}_{2}$ emission, a trend of increasing in all types of volatiles coal is observed. Taking low volatiles as standard for comparison, for coal mass flow rate of $0.1 \mathrm{~kg} / \mathrm{s}$, there is an increase of $22.85 \%$ in medium volatiles whereas the increase of $14.48 \%$ for high volatiles coal is observed. For the mass flow rate of $0.3 \mathrm{~kg} / \mathrm{s}$, there is an increase of $7.30 \%$ in medium volatiles whereas it is about $7.52 \%$ increase for high volatiles coal is observed. Coal mass flow rate, from $0.1 \mathrm{~kg} / \mathrm{s}$ to $0.3 \mathrm{~kg} / \mathrm{s}$, there is an overall increase of $166.70 \%$ for low volatiles, an increase of $128.61 \%$ for medium volatiles and an increase of $115.45 \%$ for high volatiles coal in $\mathrm{CO}_{2}$ emission is observed.

\section{CONCLUSION}

For the analysis of pulverized coal combustion, a two-dimensional rectangular furnace has been chosen and steady-state analysis has been carried for different types of coals viz., low volatiles coal, medium volatiles coal and high volatiles coal. A parametric analysis has been done by varying the top air velocity, bottom air velocity, air temperature, wall temperature and mass flow rate of coal for an effective combustion environment.

From results, it has been concluded that, as top air velocity increases, peak temperature decreases, heat transfer rate decreases, $\mathrm{NO}$ emission decreases, $\mathrm{CO}$ emission first increases and then decreases for medium volatiles and high volatiles coal whereas increases for low volatiles coal and $\mathrm{CO}_{2}$ emission decreases. As bottom air velocity increases, peak temperature first increases and then decreases for medium and high volatiles coal, heat transfer rate decreases for low volatiles, first increases and then decreases for medium volatiles whereas increases for high volatiles coal, $\mathrm{NO}_{\mathrm{x}}$ emission first increases and then decreases medium and high volatiles whereas decreases for low volatiles coal, CO and $\mathrm{CO}_{2}$ emission decreases for all types. As air temperature increases, peak temperature increases, heat transfer rate increases, $\mathrm{NO}_{\mathrm{x}}$ emission increases, $\mathrm{CO}$ emission increases for low and medium volatiles whereas decreases for high volatiles coal and $\mathrm{CO}_{2}$ emission increases for all types. As wall temperature increases, peak temperature increases, heat transfer rate increases, $\mathrm{NO}$ emission increases, $\mathrm{CO}$ emission increases and $\mathrm{CO}_{2}$ emission also increases. As the mass flow rate of coal increases, peak temperature increases, heat transfer rate increases, $\mathrm{NO}_{\mathrm{x}}$ emission first increases and then decreases for medium and high volatiles whereas increases for low volatiles coal, $\mathrm{CO}$ and $\mathrm{CO}_{2}$ emission increase. Low volatiles coal may be neglected for the combustion process whereas medium volatiles coal and high volatiles coals have their maximum equal importance under stated boundary conditions. 
As a part of the future study, a three-dimensional unsteady state analysis of the system can be modeled for a closer picture of the real situation.

\section{ACKNOWLEDGMENT}

Authors are thankful to the NIT Raipur (CG), INDIA for allowing us to use the computational and library facility of the institute. Authors are also very thankful to all the referenced researchers, who have contributed to the research of combustion modeling. Their methods and findings are certainly the inspiration for present research work.

\section{NOMENCLATURE}

$C_{1} \quad$ Mass diffusion limited rate constant

$C_{2} \quad$ Kinetics limited rate pre-exponential factor

$E \quad$ Kinetics limited rate activation energy, $\mathrm{KJ} / \mathrm{mol}$

$A_{p} \quad$ Surface area of coal particles, $\mathrm{m}^{2}$

$p_{\text {ox }} \quad$ Partial pressure of oxidant species, $\mathrm{Pa}$

$m_{p} \quad$ Mass of particle, $\mathrm{kg}$

$T \quad$ Temperature of particle, $\mathrm{K}$

$T_{\infty} \quad$ Surrounding temperature, $\mathrm{K}$

$D_{T, j} \quad$ Thermal diffusion coefficient for species $\mathrm{j}$ in the mixture, $\mathrm{m}^{2} / \mathrm{s}$

$D_{j, m} \quad$ Mass diffusion coefficient for species $\mathrm{j}$ in the mixture, $\mathrm{m}^{2} / \mathrm{s}$

$D \quad$ Diffusivity, $\mathrm{m}^{2} / \mathrm{s}$

Sc Schmidt number

$N \quad$ Refractive index of the medium

$f \quad$ Fraction

$m_{p, 0} \quad$ Initial particle mass, $\mathrm{kg}$

$A_{0} \quad$ Rate constant, $1 / \mathrm{s}$

I Radiation intensity, W/sr

$C_{p} \quad$ Specific heat capacity of particle, $\mathrm{kJ} / \mathrm{kg} \cdot \mathrm{K}$

Greek symbols

$\sigma$

Stephen Boltzmann constant, $\mathrm{W} / \mathrm{m}^{2} \mathrm{~K}^{4}$

$\varepsilon \quad$ Emissivity

$\mu \quad$ Viscosity, $\mathrm{kg} / \mathrm{m} \cdot \mathrm{s}$

$\emptyset \quad$ Thermochemical scalars

Subscripts

$P \quad$ Particle

$t \quad$ Turbulent

j Species

$T \quad$ Thermal

$v, 0 \quad$ Volatiles initially present

w, $\quad$ Evaporating/boiling material present

\section{REFERENCES}

[1] Holkar R. CFD Anlysis of Pulverised-Coal Combustion of Burner Used In Furnace with Different Radiation Models. IOSR J Mech Civ Eng 2013;5:25-34.

[2] Marek E, Świątkowski B. Experimental studies of single particle combustion in air and different oxy-fuel atmospheres. Appl Therm Eng 2014;66:35-42. https://doi.org/https://doi.org/10.1016/j.applthermaleng.2014.01.070.

[3] Bhuiyan AA, Naser J. CFD modelling of co-firing of biomass with coal under oxy-fuel combustion in a large scale power plant. Fuel 2015;159:150-68. https://doi.org/https://doi.org/10.1016/j.fuel.2015.06.058.

[4] Elattar HF, Stanev R, Specht E, Fouda A. CFD simulation of confined non-premixed jet flames in rotary kilns for gaseous fuels. Comput Fluids 2014;102:62-73. https://doi.org/https://doi.org/10.1016/j.compfluid.2014.05.033.

[5] Yu B, Lee S, Lee C-E. Study of NOx emission characteristics in CH4/air non-premixed flames with exhaust 
Journal of Thermal Engineering, Research Article, Vol. 6, No. 6, Special Issue 12, pp. 323-353, December, 2020 gas recirculation. Energy 2015;91:119-27. cylinder diesel engine simulation. Appl Energy 2012;90:271-9. https://doi.org/https://doi.org/10.1016/j.apenergy.2010.12.075.

[7] Yin C. On gas and particle radiation in pulverized fuel combustion furnaces. Appl Energy 2015;157:554-61. https://doi.org/https://doi.org/10.1016/j.apenergy.2015.01.142.

[8] Gómez MA, Porteiro J, Patiño D, Míguez JL. Eulerian CFD modelling for biomass combustion. Transient simulation of an underfeed pellet boiler. Energy Convers Manag 2015;101:666-80. https://doi.org/https://doi.org/10.1016/j.enconman.2015.06.003.

[9] Cheng X, Ng HK, Gan S, Ho JH, Pang KM. Development and validation of a generic reduced chemical kinetic mechanism for CFD spray combustion modelling of biodiesel fuels. Combust Flame 2015;162:235470. https://doi.org/https://doi.org/10.1016/j.combustflame.2015.02.003.

[10] Gövert S, Mira D, Kok JBW, Vázquez M, Houzeaux G. Turbulent combustion modelling of a confined premixed jet flame including heat loss effects using tabulated chemistry. Appl Energy 2015;156:804-15. https://doi.org/https://doi.org/10.1016/j.apenergy.2015.06.031.

[11] Taamallah S, Vogiatzaki K, Alzahrani FM, Mokheimer EMA, Habib MA, Ghoniem AF. Fuel flexibility, stability and emissions in premixed hydrogen-rich gas turbine combustion: Technology, fundamentals, and numerical simulations. Appl Energy 2015;154:1020-47. https://doi.org/https://doi.org/10.1016/j.apenergy.2015.04.044.

[12] Ziani L, Chaker A, Chetehouna K, Malek A, Mahmah B. Numerical simulations of non-premixed turbulent combustion of CH4-H2 mixtures using the PDF approach. Int J Hydrogen Energy 2013;38:8597-603. https://doi.org/https://doi.org/10.1016/j.ijhydene.2012.11.104.

[13] Li P, Wang F, Mi J, Dally BB, Mei Z, Zhang J, et al. Mechanisms of NO formation in MILD combustion of CH4/H2 fuel blends. Int J Hydrogen Energy 2014;39:19187-203. https://doi.org/https://doi.org/10.1016/j.ijhydene.2014.09.050.

[14] Rahmanian B, Safaei MR, Kazi SN, Ahmadi G, Oztop HF, Vafai K. Investigation of pollutant reduction by simulation of turbulent non-premixed pulverized coal combustion. Appl Therm Eng 2014;73:1222-35. https://doi.org/https://doi.org/10.1016/j.applthermaleng.2014.09.016.

[15] Fischer P, Schiemann M, Scherer V, Maas P, Schmid G, Taroata D. A numerical model of the combustion of single lithium particles with CO2. Fuel 2015;160:87-99. https://doi.org/https://doi.org/10.1016/j.fuel.2015.07.033.

[16] Zhou L, Liu Z, Wang Z. Numerical study of influence of biofuels on the combustion characteristics and performance of aircraft engine system. Appl Therm Eng 2015;91:399-407. https://doi.org/https://doi.org/10.1016/j.applthermaleng.2015.08.018.

[17] Muppala S, Manickam B, Dinkelacker F. A Comparative Study of Different Reaction Models for Turbulent Methane/Hydrogen/Air Combustion. J Therm Eng 2015;1:367. https://doi.org/10.18186/jte.60394.

[18] Karyeyen S, Ilbas M. Experimental and numerical analysis of turbulent premixed combustion of low calorific value coal gases in a generated premixed burner. Fuel 2018;220:586-98. https://doi.org/https://doi.org/10.1016/j.fuel.2018.02.052.

[19] Mao Z, Zhang L, Zhu X, Zhou D, Liu W, Zheng C. Investigation on coal moderate or intense low-oxygen dilution combustion with high-velocity jet at pilot-scale furnace. Appl Therm Eng 2017;111:387-96. https://doi.org/https://doi.org/10.1016/j.applthermaleng.2016.09.085.

[20] Saha M, Dally BB, Medwell PR, Chinnici A. Effect of particle size on the MILD combustion characteristics of pulverised brown coal. Fuel Process Technol 2017;155:74-87. https://doi.org/https://doi.org/10.1016/j.fuproc.2016.04.003.

[21] Sudarma A, Al-Witry A, Morsy M. Rans numerical simulation of lean premixed bluff body stabilized combustor: Comparison of turbulence models. J Therm Eng 2017;3:1561-73. https://doi.org/10.18186/journal-of-thermal-engineering.353668.

[22] Li S, Xu Y, Gao Q. Measurements and modelling of oxy-fuel coal combustion. Proc Combust Inst 2019;37:2643-61. https://doi.org/https://doi.org/10.1016/j.proci.2018.08.054.

[23] Abay M. Computational fluid dynamics analysis of flow and combustion of a diesel engine. J Therm Eng 2018;4:1878-95. https://doi.org/10.18186/journal-of-thermal-engineering.388333.

[24] Angeline A. Power generation from combusted "Syngas" using hybrid thermoelectric generator and forecasting the performance with ANN technique. J Therm Eng 2018;4:2149-68. https://doi.org/10.18186/journal-of-thermal-engineering.433806. 
Journal of Thermal Engineering, Research Article, Vol. 6, No. 6, Special Issue 12, pp. 323-353, December, 2020

[25] Naik MPK, Dewangan SK. CFD modeling of non-premixed combustion of pulverized coal in a furnace. Comput Therm Sci 2017;9:195-211. https://doi.org/10.1615/ComputThermalScien.2017019027.

[26] Pillai KK. Influence of Coal Type on Devolatilization and Combustion in Fluidized Beds. J Inst Energy 1981;54:142-50. 
Journal of Thermal Engineering, Research Article, Vol. 6, No. 6, Special Issue 12, pp. 323-353,

December, 2020

APPENDIX A

A1: Proximate and ultimate analysis of low volatiles coal

Proximate analysis:

\begin{tabular}{|c|c|}
\hline Proximate analysis & Weight \% (dry) \\
\hline Volatiles & 9.38 \\
\hline Char (C(s)) & 82.12 \\
\hline Ash & 6.5 \\
\hline Moisture & 2 \\
\hline
\end{tabular}

Ultimate analysis:

\begin{tabular}{|c|c|c|}
\hline Element & Wt \% (dry ash free basis) & Mole fraction \\
\hline $\mathrm{C}$ & 88.55 & 0.61321 \\
\hline $\mathrm{H}$ & 4.19 & 0.34577 \\
\hline $\mathrm{O}$ & 2.83 & 0.01471 \\
\hline $\mathrm{N}$ & 1.48 & 0.02631 \\
\hline $\mathrm{S}$ & 2.95 & (Nitrogen and sulfur taken together) \\
\hline
\end{tabular}

Lower calorific value of the low volatiles coal is $2.4 \times 10^{7} \mathrm{j} / \mathrm{Kg}$.

A2: Proximate and ultimate analysis of medium volatiles coal

Proximate analysis:

\begin{tabular}{|c|c|}
\hline Proximate analysis & Weight \% (dry) \\
\hline Volatiles & 27.5 \\
\hline Char (C(s)) & 64 \\
\hline Ash & 6.5 \\
\hline Moisture & 2 \\
\hline
\end{tabular}

Ultimate analysis:

\begin{tabular}{|c|c|c|}
\hline Element & Wt \% (dry ash free basis) & Mole fraction \\
\hline $\mathrm{C}$ & 89.3 & 0.58358 \\
\hline $\mathrm{H}$ & 5.0 & 0.38937 \\
\hline $\mathrm{O}$ & 3.4 & 0.01668 \\
\hline $\mathrm{N}$ & 1.5 & 0.01037 \\
\cline { 1 - 2 } $\mathrm{S}$ & 0.8 & (Nitrogen and sulfur taken together) \\
\hline
\end{tabular}

Lower calorific value of the medium volatiles coal is $2.93 \times 10^{7} \mathrm{~J} / \mathrm{Kg}$.

A3: Proximate and ultimate analysis of high volatiles coal

Proximate analysis:

\begin{tabular}{|c|c|}
\hline Proximate analysis & Weight \% (dry) \\
\hline Volatiles & 41.78 \\
\hline Char $(\mathrm{C}(\mathrm{s}))$ & 49.72 \\
\hline Ash & 6.5 \\
\hline Moisture & 2 \\
\hline
\end{tabular}


Journal of Thermal Engineering, Research Article, Vol. 6, No. 6, Special Issue 12, pp. 323-353,

December, 2020

Ultimate analysis:

\begin{tabular}{|c|c|c|}
\hline Element & Wt \% (dry ash free basis) & Mole fraction \\
\hline $\mathrm{C}$ & 80.2 & 0.50218 \\
\hline $\mathrm{H}$ & 5.73 & 0.42755 \\
\hline $\mathrm{O}$ & 7.89 & 0.03709 \\
\hline $\mathrm{N}$ & 1.45 & 0.03318 \\
$\mathrm{~S}$ & 4.73 & (Nitrogen and Sulfur taken together) \\
\hline
\end{tabular}

Lower calorific value of the high volatiles coal is $3.64 \times 10^{7} \mathrm{j} / \mathrm{Kg}$.

A4: Parameters those are constant for top air velocity variation

\begin{tabular}{|l|c|}
\hline \multicolumn{1}{|c|}{ Parameter } & Value \\
\hline Bottom air velocity & $50 \mathrm{~m} / \mathrm{s}$ \\
\hline Air temperature & $1500 \mathrm{~K}$ \\
\hline Top wall boundary temperature & $300 \mathrm{~K}$ \\
\hline Mass flow rate of coal & $0.1 \mathrm{~kg} / \mathrm{s}$ \\
\hline
\end{tabular}

A5: Parameters those are constant for bottom air velocity variation

\begin{tabular}{|l|c|}
\hline \multicolumn{1}{|c|}{ Parameter } & Value \\
\hline Top air velocity & $15 \mathrm{~m} / \mathrm{s}$ \\
\hline Air temperature & $1500 \mathrm{~K}$ \\
\hline Top wall boundary temperature & $300 \mathrm{~K}$ \\
\hline Mass flow rate of coal & $0.1 \mathrm{~kg} / \mathrm{s}$ \\
\hline
\end{tabular}

A6: Parameters those are constant for air temperature variation

\begin{tabular}{|l|c|}
\hline \multicolumn{1}{|c|}{ Parameter } & Value \\
\hline Top air velocity & $15 \mathrm{~m} / \mathrm{s}$ \\
\hline Bottom air velocity & $50 \mathrm{~m} / \mathrm{s}$ \\
\hline Top wall boundary temperature & $300 \mathrm{~K}$ \\
\hline Mass flow rate of coal & $0.1 \mathrm{~kg} / \mathrm{s}$ \\
\hline
\end{tabular}

A7: Parameters those are constant for wall temperature variation

\begin{tabular}{|l|c|}
\hline \multicolumn{1}{|c|}{ Parameter } & Value \\
\hline Top air velocity & $15 \mathrm{~m} / \mathrm{s}$ \\
\hline Bottom air velocity & $50 \mathrm{~m} / \mathrm{s}$ \\
\hline Air temperature & $1500 \mathrm{~K}$ \\
\hline Mass flow rate of coal & $0.1 \mathrm{~kg} / \mathrm{s}$ \\
\hline
\end{tabular}


Journal of Thermal Engineering, Research Article, Vol. 6, No. 6, Special Issue 12, pp. 323-353, December, 2020

A8: Parameters those are constant for mass flow rate variation

\begin{tabular}{|l|c|}
\hline \multicolumn{1}{|c|}{ Parameter } & Value \\
\hline Top air velocity & $15 \mathrm{~m} / \mathrm{s}$ \\
\hline Bottom air velocity & $50 \mathrm{~m} / \mathrm{s}$ \\
\hline Air temperature & $1500 \mathrm{~K}$ \\
\hline Top wall boundary temperature & $300 \mathrm{~K}$ \\
\hline
\end{tabular}

